\title{
The habit-driven life: Accounting for inertia in departure time choices for commuting trips
}

\author{
Mikkel Thorhauge ${ }^{\mathrm{a}, *}$, Joffre Swait ${ }^{\mathrm{b}}$, Elisabetta Cherchi ${ }^{\mathrm{c}}$ \\ ${ }^{a}$ Department of Technology, Management and Economics, Technical University of Denmark, Denmark \\ ${ }^{\mathrm{b}}$ Erasmus School of Health Policy \& Management, Erasmus University Rotterdam, the Netherlands \\ ${ }^{\mathrm{c}}$ School of Engineering, Newcastle University, United Kingdom
}

\section{A R T I C L E I N F O}

\section{Keywords:}

Departure time choice

Inertia

Habit

Integrated choice and latent variable model

\begin{abstract}
A B S T R A C T
This paper aims to explicitly account for the impact of inertia (or habit) on departure time decisions, and explore (1) to what extent departure time is influenced by inertia, (2) what influences individuals' inertia with respect to departure time decisions, and (3) to what extent it impacts transport policies. We estimate an integrated choice and latent variable (ICLV) model using a stated preference survey for morning car commuters in the Greater Copenhagen Area. We interact the rescheduling components in the Scheduling Model (SM) with the latent variable Inertia. The modelling results show that higher levels of inertia yields higher rescheduling penalties and lower willing to shift departure time. Furthermore, we find that inertia in departure time is influenced by gender, presence of children in the household as well as work type. We test the behavioral responses to demand management policies for segments with different inertia, and find that the least inertial segment showed the highest substitution patterns, while the most inertial segment show the lowest substitution patterns. Finally, we compared the ICLV model to a reference model without inertia, and find that the effects of the demand management strategy is overestimated if inertia is neglected.
\end{abstract}

\section{Introduction}

Congestion is an increasing problem around the world. As in many transport problems, congestion can be addressed in two ways: increasing capacity or reducing demand. However, it is commonly acknowledged that infrastructure upgrades (alone) is not a long term solution for congestion as induced traffic is quickly generated as a consequence of increased capacity (Arnott and Small, 1994; Hansen and Huang, 1997; Noland and Lem, 2002). Therefore, city planners around the world have turned their attention towards traffic demand strategies in order to shift the demand toward other modes than cars or, since people are more likely to change their departure time than mode (Bianchi et al., 1998; Hendrickson and Planke, 1984; Hess et al., 2007; Kroes et al., 1996), to spread the peak car traffic utilizing some of the spare capacity outside the rush hours.

There is an extensive literature on departure time, but this has been almost exclusively studied from a microeconomic point of view based on the seminal work of Small (1982). The scheduling model developed by Small has been extended in various ways to account for the fact that scheduling of trips and activities is indeed planned in relation to other activities. The majority of those studies (Arellana et al., 2012; de Jong et al., 2003; Hess et al., 2007) extended the scheduling model by explicitly accounting for the joint outbound and homebound trips around a main activity (usually work or education). In addition to that, Thorhauge et al.

\footnotetext{
* Corresponding author.

E-mail addresses: mtho@dtu.dk (M. Thorhauge), swaitjr@eshpm.eur.nl (J. Swait), Elisabetta.Cherchi@newcastle.ac.uk (E. Cherchi).
} 
(2016a) showed that the full daily activity pattern (not just trips around the main activity) play an important role in the departure time choice, as well as the presence of constraints on various daily activities other than work.

In parallel, a growing literature has proved that many individual transport decisions are also affected by psychological effects (see, e.g., Bhat et al., 2015; Daziano and Bolduc, 2013; Jensen et al., 2013; Kamargianni et al., 2014; Paulssen et al., 2014), however to our best knowledge Thorhauge et al. (2017, 2016b) is the only study which enhances the choice model for departure time decisions with latent variables according to the Theory of Planned Behavior (Ajzen, 1991).

Referring to the constructs of the Theory of Planned Behavior (TPB), Lanzini and Khan (2017) provides a meta-analysis of 58 studies, and concludes that intentions, habits and past use are the primary determinants in explaining transportation mode choice. More specifically, several studies (e.g., Carrus et al., 2008; Conner et al., 2000; Ouellette, 1998; Thøgersen, 2006) have found that the frequency of past behavior is the best predictor of future behavior and tends to explain most of the variance in intentions (or behavior), often rendering most other predictors as not significant. Furthermore, according to Triandis' model of interpersonal behavior, habit strength "is measured by the number of times the act has already been performed by the person" (Triandis, 1977, p. 10).

According to the Oxford Dictionary habit is defined as "An automatic reaction to a specific situation", while inertia is defined as "A tendency to ... remain unchanged". Although sometime used interchangeably, inertia has a broader definition and encompasses habit. Habitual behavior reveals itself as inertia, but the same is not (necessarily) true the other way around. A behavior can be inertial but not habitual, Inertia, in fact, can be caused also by the need to deal with complex decisions and avoid the continual reevaluation of the same choice, by external factors such as limited information or the influence of social peers and societal norms. At the same time inertia (or its manifestation, which is the frequency of the repeated behavior) can be strengthened by the presence of constraints (e.g. workers go to work every day because they have a job they need to attend). In practice, it is very difficult to untangle the different components of inertia, and in particular habit, because a behavior that initially is inertial because of the presence of a constraint could for example become habitual over time.

It has been argued that the relationship between past and future behavior is mainly a reflection of temporal stability (Ajzen, 2002, 1991), i.e. "the factors that influenced the past behaviour continue to influence the intentions and future behaviour, but past behaviour does not cause future behaviour" (Knussen et al., 2004, p. 238). This suggests that inertia, should indeed be treated as a latent effect when studying the behavioral outcome. Thus, future behavior is likely to be similar to previous behavior if the (latent) inertia is strong. Habit and inertia have also been extensively studied in the transport literature within a microeconomic approach, in the context of mode of mode (Bamberg et al., 2003; Cantillo et al., 2007; Chatterjee, 2011; Cherchi et al., 2014; Cherchi and Manca, 2011; Gardner, 2009; Golob et al., 1997; Gärling and Axhausen, 2003; Sharmeen and Timmermans, 2014; Srinivasan and Bhargavi, 2007; Yáñez et al., 2009), vehicle purchase (Bauer, 2018; Jansson et al., 2009), car engine type (Valeri and Cherchi, 2016), destination (Zong et al., 2019), route (Bogers et al., 2005; He et al., 2014; Prato et al., 2012), residential location (Ralph and Brown, 2017) and parking choice (van der Waerden et al., 2015). Cherchi et al. (2014) have studied the role of habitual behavior in mode choice, using a hybrid approach that assumes that inertia is revealed by past behavior but recognizes that past behavior is only an indicator of habitual behavior, the true process behind the formation of habitual behavior being latent. From this literature, it seems clear that inertia affects almost all transport choices. There is then no reason to believe that a key choice like the departure time would not be affected by habit. Peer et al. (2015) studied the difference between long-run and short-run scheduling preferences. They assumed that daily routines were fixed in the short-run, but could be changed in the long-run, and found that individuals value scheduling higher in the short-run, which reflects that constraints are often more binding in the short run, while travel time is valued higher in the long-run, probably due to the fact that travel time reductions can be better exploited in the long run. However, to our knowledge no one has explicitly modelled the underlying habit or inertia with respect to departure times and studied if and to what extend this affects departure time decisions.

Measuring inertial behavior in departure time is not straightforward because departure time decisions can rarely be seen as an isolated decision, but should be seen in relation to the full activity schedule. In particular, the activity schedule is typically planned at least at a daily level, hence the departure time decision for some trip in a given period of the day is likely to influence departure time decisions for other trips in another time of the day. We therefore believe that in order to correctly account for inertia in departure time decisions we should have indicators for multiple time periods during the day, e.g., morning, afternoon, and evening.

Against the background described above, the objective of this study is to investigate to which extent inertia affects departure time decisions and whether the impact is direct in the preference for a specific departure time or indirect due to the role of the daily activities and constraints to preferences for travel time, delays, etc. The contribution of this paper is threefold. We explore for the first time (1) the influence of inertial behavior in the departure time decisions, (2) what influences individuals' inertia with respect to departure time decisions, and (3) the policy implications in terms of forecasting the potential of changing commuters to travel outside of rush hours, e.g., due to traffic demand management (TDM) strategies such as congestion charging. Our research hypotheses are:

H1. The preferences for rescheduling depend on the level of individuals' Inertia. More specifically, we expect that individuals with high inertia will have higher (marginal) disutility for rescheduling their departure time, and thus their willingness to shift departure time will be lower.

H2. Certain individuals are more likely to be inertial because of their life situation, e.g., presence of children in the household and fixed working hours.

H3. Segmenting the population based on their degree of inertia will produce widely different responses in policy analysis for different segments.

Our study will focus on departure time decisions for morning car commuters. We use data from a stated choice experiment for 
departure time decisions for morning car commuters in the Greater Copenhagen Area. We follow the approach from Cherchi et al. (2014) and estimate an Integrated Choice and Latent Variable (ICLV) model, where the frequency of the trips performed in various periods of the day are used as an indicator of the latent inertial behavior that affects the perception of the rescheduling penalties.

The remainder of this paper is structured as follows: In Section 2 we describe the survey and data, while Section 3 presents the methodological framework and model specifications. Section 4 contains the modelling results and policy implications, and, finally, Section 5 presents a discussion of and conclusions derived from the findings in this paper.

\section{Data}

In this section we describe the data used for this study: in Section 2.1 we cover the survey and data collection, while in Section 2.2 we provide an analysis of some key sample characteristics.

\subsection{Survey and data collection}

The data used in this paper is collected as part of a departure time study in the Greater Copenhagen Area (Thorhauge, 2015). The survey was targeted towards individuals commuting to work in the CBD area by car, and travelling between 6:00-10:00 A.M. The data was collected among employees at universities, public organizations and private companies in Copenhagen using an online questionnaire. For a comprehensive description of the questionnaire design, data collection, and sample description we refer to Thorhauge et al. (2016a, 2016b). Below we will provide a brief overview of the questionnaire as well as an in-depth description of the parts relevant for this study.

The questionnaire is based on the Danish National Travel Survey (Transportvaneundersøgelsen, TU, Christiansen and Skovgaard, 2015), but modified specifically to study departure time choices. It contains various socio-demographics and a full travel diary including all trips and (out-of-home) activities performed during a $24 \mathrm{~h}$ period (starting and ending at 3:00 AM). More specifically, for each trip we collected information about the departure time, duration, length, mode, destination, and purpose of the trip.

Relevant for this work, for each trip reported in the trip diary, we also asked how frequently respondents performed a trip similar to the one reported, i.e. with same origin, destination, purpose, mode and departure time. This response was recorded as categorical, the options being: daily, several times a week, weekly, several times a month, monthly, or less than once a month. The responses are represented on a 6-point Likert scale (Likert, 1932), where 6 represents a very inertial behavior (i.e. daily) and 1 represents a very non-inertial behavior (i.e. less than once a month).

For each trip reported in the trip diary we also asked about the temporal flexibility of that trip and the corresponding activity on the specific day of the survey. In particular, we asked if the respondents had constraints with respect to their arrival time (e.g., at work) on that specific day (of the survey). Such a constraint may vary from day-to-day, e.g. due to a scheduled meeting. We also asked the respondents how their work is scheduled, i.e. if they have fixed work (start) hours or flexible work (start) hours. In contrast to the daily constraints, the fixed work hours captures a general more long term work agreement with the employer. For example, an individual who work in a store usually have a fixed working schedule, while individuals working in an office usually do not. We also presented respondents with a stated choice experiment (Louviere et al., 2000), asking them to choose among three departure time options for their morning commute trip. The choice experiment describes alternatives in term of time of departure, travel time and travel time reliability, and travel cost. Prior to presenting the stated choice experiment we asked about the preferred arrival time (PAT). More specifically, we asked about respondents preferred arrival time under normal traffic conditions, but as a confirmation we checked that the stated arrival time would also hold in a hypothetical situation without congestion. This was the case for almost all $(92 \%)$ respondents. The design was then customized based on the preferred arrival time and the trip described by each respondent as part of a revealed preference (RP) questionnaire administered before the stated preference design. The three departure-time options presented in the choice tasks consist of one alternative within a few minutes around what was declared by the respondent in the RP survey, while the two remaining options represent early and late departure times. Fig. 1 presents an example of the choice task. Each respondent was presented with 9 choice tasks. We note that although the three alternatives are labeled as journey A, B and C there is a clear time ordering to them because the first attribute of the design is the departure time and the three alternatives in each task always had different departure time (early, the same and late). For more information on the stated choice experiment we refer to Thorhauge et al. (2014).

\subsection{Sample characteristic}

Since the study is focused on morning car commuters in the Greater Copenhagen Area, the data was cleaned to only include individuals who (1) live and work in the Greater Copenhagen Area, (2) commute to work by car, (3) travel to work between 6 and 10 $\mathrm{AM}$, and (4) replied to at least one choice task. Furthermore, we removed incomplete interviews as well as interviews where individuals had stated that they did not return back home that day. The final sample consists of 287 individuals who provided a total of 2525 observations $^{1}$. The sample is equally split across gender (51.9\% males), while mainly composed of couples (82.6\% of respondents have a spouse or partner) with a university degree (93.4\%). 59.2\% of the respondents have kids, $30.1 \%$ have fixed work

\footnotetext{
${ }^{1}$ Two hundred thirty-nine respondents replied all 9 choice tasks; 40 respondents replied to 8 choice tasks; 6 respondents replied to 7 choice tasks; 2 respondents replied to 6 choice tasks. The choice tasks missing are evenly spread among the 9 choice tasks
} 
Which option would you select?

\begin{tabular}{|c|c|c|c|}
\hline & Journey A & Journey B & Journey C \\
\hline Departure time & 08:00 & 07:30 & 07:00 \\
\hline \multirow[t]{2}{*}{ Travel time } & $\begin{array}{l}4 \text { out of } 5 \text { times the travel } \\
\text { time will be } 24 \text { minutes } \\
\text { (arrival time 08:24) }\end{array}$ & $\begin{array}{l}4 \text { out of } 5 \text { times the travel } \\
\text { time will be } 30 \text { minutes } \\
\text { (arrival time 08:00) }\end{array}$ & $\begin{array}{l}4 \text { out of } 5 \text { times the travel } \\
\text { time will be } 21 \text { minutes } \\
\text { (arrival time } 07: 21 \text { ) }\end{array}$ \\
\hline & $\begin{array}{l}1 \text { out of } 5 \text { times the travel } \\
\text { time will be } 39 \text { minutes } \\
\text { (arrival time 08:39) }\end{array}$ & $\begin{array}{l}1 \text { out of } 5 \text { times the travel } \\
\text { time will be } 45 \text { minutes } \\
\text { (arrival time 08:15) }\end{array}$ & $\begin{array}{l}1 \text { out of } 5 \text { times the travel } \\
\text { time will be } 31 \text { minutes } \\
\text { (arrival time 07:31) }\end{array}$ \\
\hline Cost & $10 \mathrm{DKK}$ & 16 DKK & 16 DKK \\
\hline Your choice? & 0 & 0 & 0 \\
\hline
\end{tabular}

Fig. 1. Example choice task in the stated choice experiment.

start times, and $48.6 \%$ declared temporal constraints at work for the specific day of the survey. On average, the respondents are 46.9 (Std. Dev.: 10.6) years old, performed 3.2 (Std. Dev.: 1.3) trips/day, work 42.1 (Std. Dev.: 8.3) hours per week, and had an income of DKK 559,100 (Std. Dev.: 241,100). Since the sample is collected at typical white-collar work places, the sample cannot claim to be representative of the Danish (or even the Copenhagen) population. However, we believe that the sample is relevant and highly useful for the topic of this study since it includes a large share of flexible individuals (i.e., no constraints at work). This makes it likely that the inertia we are measuring is in fact due to habit, and not just solely determined by work constraints.

The chosen alternative in the choice experiment is fairly evenly split between the three alternatives: $39.4 \%$ for the early departure time, $27.2 \%$ for the current departure time, and 33.5\% for the late departure time. Fig. 2 shows the distribution of the departure and arrival time for the chosen alternative in the choice experiment. Furthermore, the figure also presents the distribution of the observed departure time (from home) and arrival time (at work), as well as the preferred arrival time at work reported by the respondents, which are aligned with the chosen departure and arrival times.

In order to measure the latent effect of inertia we use the responses on trip frequency as dependent variables. We consider the frequency reported in each of 5 time periods, as defined below. Similar to Thorhauge et al. (2016a), we define 5 overall trip chains based on main anchor points, i.e. home and work. These represents the following time periods of the day:

(1) Before Work (BW), if the (sequence of) activities/trips is part of a home-based tour realized before going to work. These

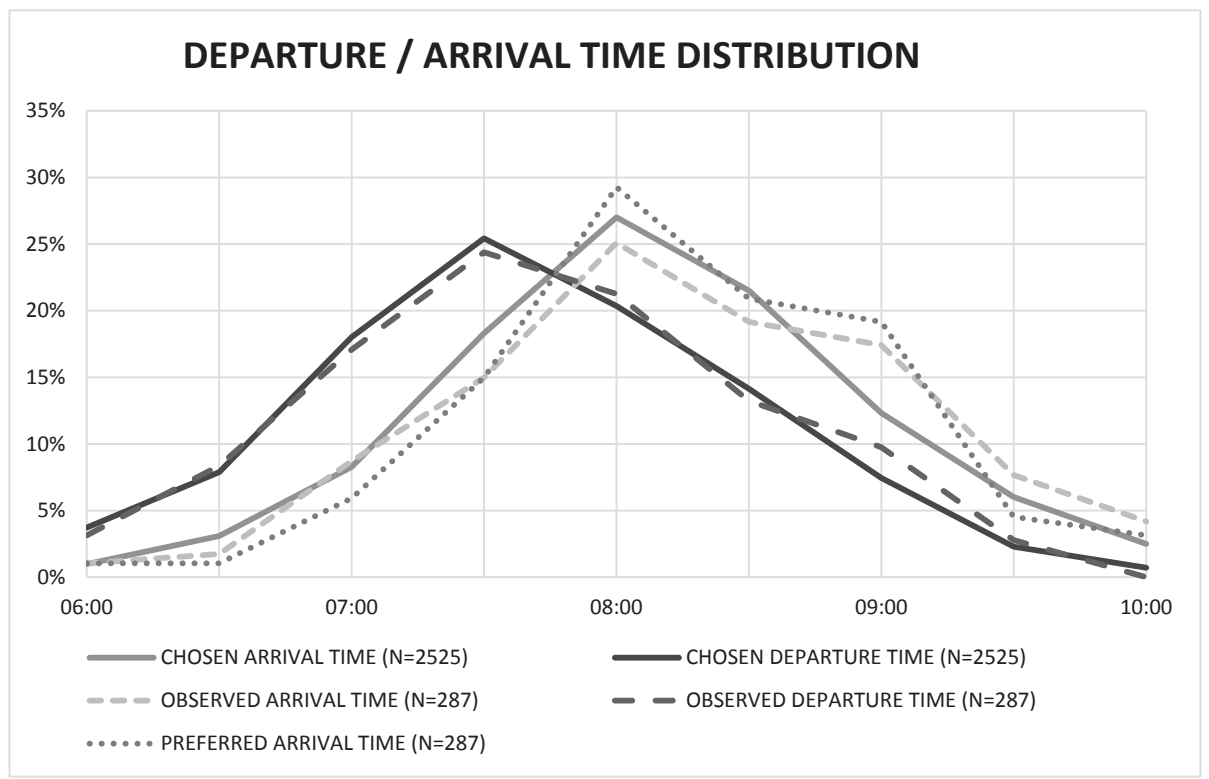

Fig. 2. Distribution of departure times (from home) and arrival times (at work). 


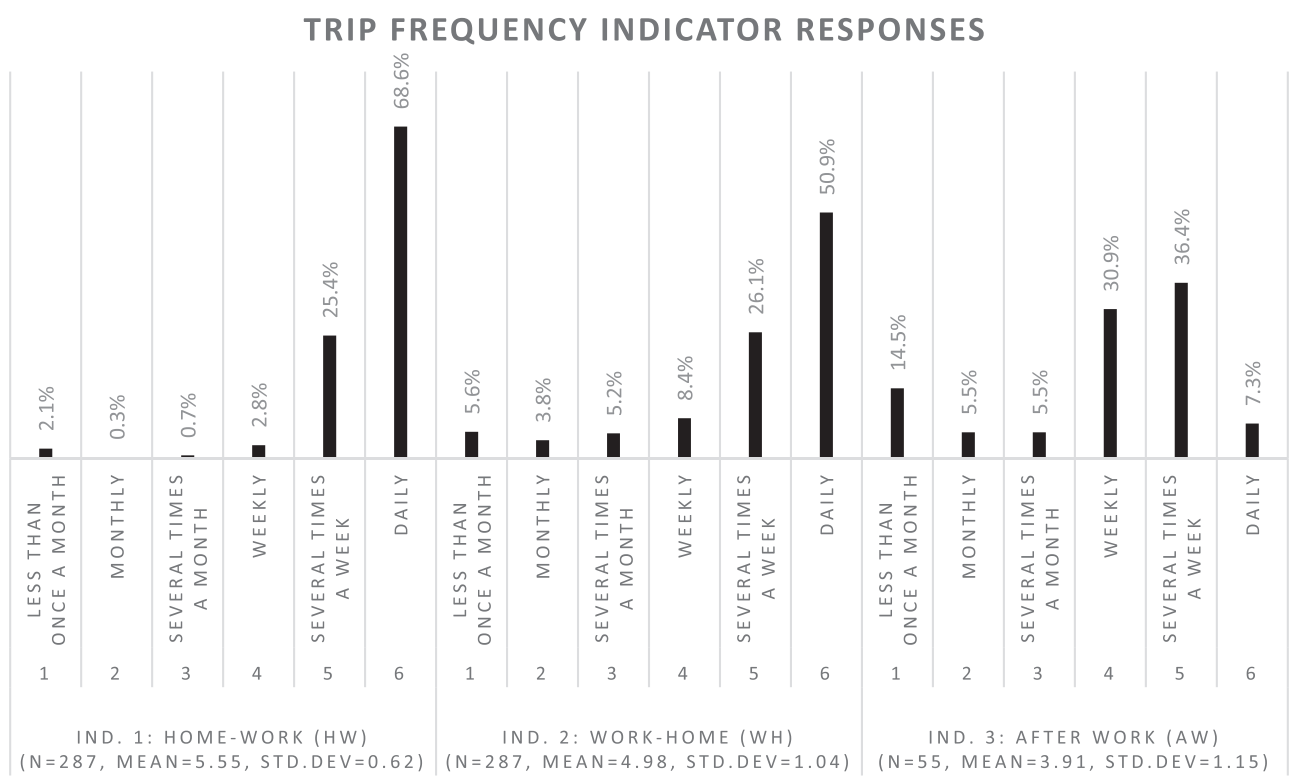

Fig. 3. Distribution of responses for trip frequency for each of the three indicators.

activities/trips - in our sample - are carried out in the morning.

(2) Home-to-Work (HW), if the (sequence of) activities/trips is realized on the way from home to work. These activities/trips - in our sample - are carried out in the morning.

(3) Work-to-Work (WW), if the (sequence of) activities/trips is part of a work-based sub-tour. These activities/trips - in our sample are carried out during the day after arrival at work and before a work-to-home or after-work tour.

(4) Work-to-Home (WH), if the (sequence of) activities/trips is realized on the way back from work to home. These activities/trips in our sample - are carried out in the afternoon/evening.

(5) After Work (AW), if the (sequence of) activities/trips is a home-based tour realized after returning home from work. These activities/trips - in our sample - are carried out in the evening.

Note that if an individual performed more than one trip in the same trip chain and these trips had different reported frequency, we then considered the most frequent trip as the observed response for that time period. Very few individuals performed trips/activities before work (BW) and as sub-tours from work (WW), so these two time periods will not be used for the remaining part of this study. Fig. 3 shows the reported frequency of the individuals' trips in the three time periods: Home-Work (HW), Work-Home (WH), and After Work (AW). The figure shows that the majority of the respondents commuting pattern is the same from day-to-day or several times a week for both the morning and afternoon commute. More specifically, two thirds of the individuals carry out their morning commute trips the same way every day, while one fourth of the individuals have morning routines which are repeated several times a week. Similar patterns can be seen for the afternoon trips, albeit the percentage of individuals with the same daily routine is a bit lower. For evening trips, note that only 55 of the respondents reported an evening trip, but among those who did, a bit less than half $(43.7 \%)$ reported that the trip was repeated either on a daily basis or several times a week. To get an insight if there are systematic differences in the reported trip frequencies, Fig. 4 and Table 1 present the cross tabulation of the indicators with various sociodemographic characteristics and the chosen alternative in the stated choice experiment. Fig. 4 seems to suggest that males are more likely to repeat the same type of trip on a daily basis, while women more often than men perform the same type of trip several times a week. The same tendency seems to occur for individuals with children compared to individuals without children. Interestingly, the figure suggests that having fixed vs. flexible work hours has little impact, except for a few of the categories where having fixed work hours seems to clearly dominate, i.e. for morning commute trips and evening trips that are carried out several times a week. In Table 1, the frequency categories were grouped from six groups into three groups in order to avoid having too few observations in some of the groups, which makes it difficult to discern overall trends due to white noise. The table seems to suggest a general tendency that individuals who frequently repeat their trips are least likely to reschedule, while the percentage of individuals who choose to reschedule increases as the frequency of the reported trip decreases.

\section{Methodology}

In order to account for inertia in a departure time context we follow the approach used in Cherchi et al. (2014), where the trip frequency is used as indicators of inertial behavior, and observed outcomes of inertia is an unobserved latent variable. In line with this research the measurement items selected should capture a general tendency to be inertial, beyond the specific choice under study. In our work we use three indicators that refer to activities performed in different periods of the day, which in our context (in 


\section{CROSS TABULATION BETWEEN TRIP FREQUENCY INDICATORS AND SOCIO DEMOGRAPHICS}

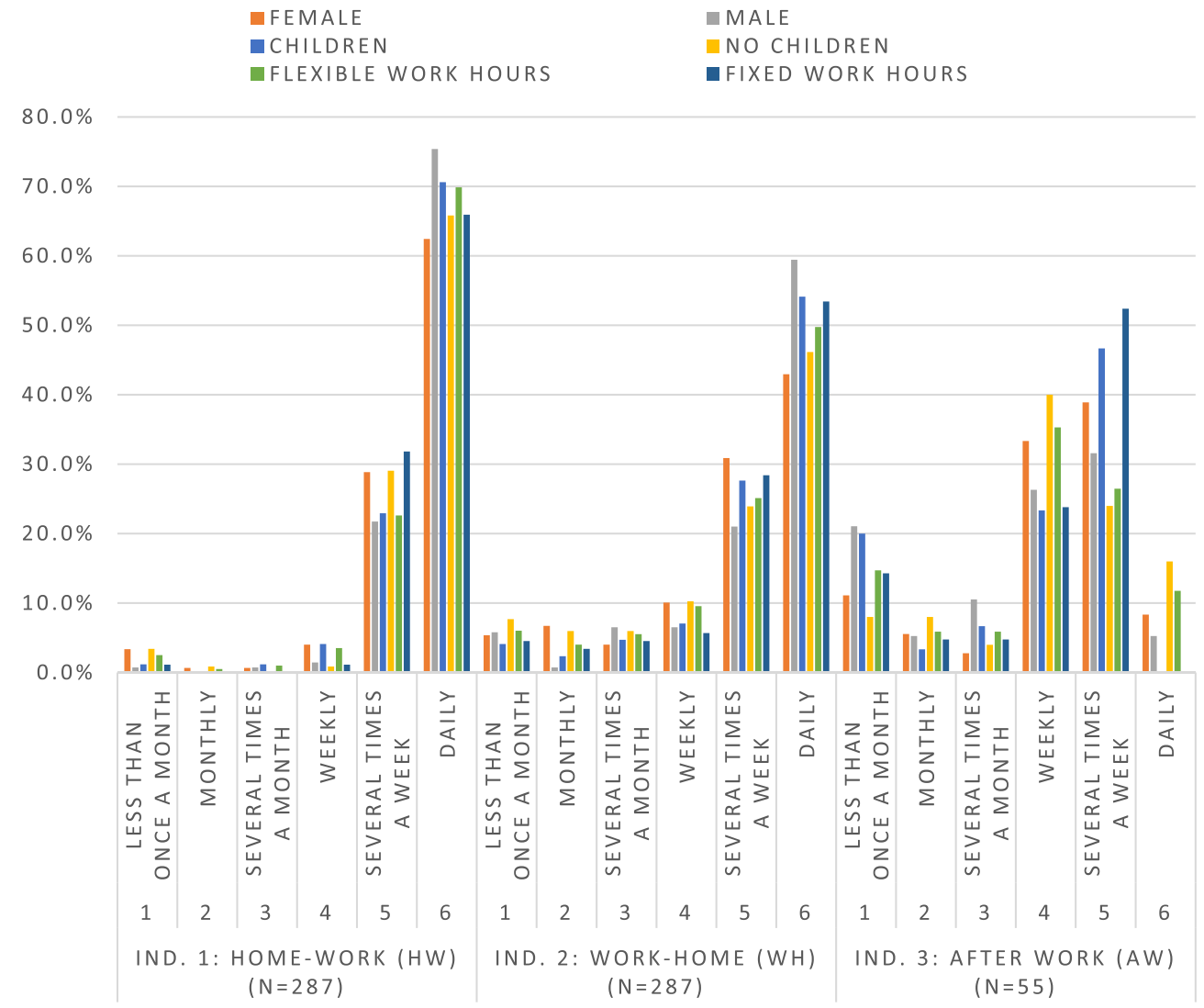

Fig. 4. Cross tabulation of individual socio-demographic characteristic and the trip frequency indicators.

line with several other researches, Bowman and Ben-Akiva, 2000) are linked within the daily activity schedule. Following the integrated choice and latent variable (ICLV) framework (Walker and Ben-Akiva, 2002), our model then consists of both a discrete choice model and a latent variable model. The latent variable model is defined as a structural equation model (SEM), while the choice model is specified as the Scheduling Model (SM; Small, 1982). The overall model framework is depicted in Fig. 5.

We expect inertia to influence the preferences towards being early and late. In addition to that we believe that departure time choice is affected by household composition as well as work constraints (which is supported by the majority of literature on departure time choices, see e.g., Thorhauge et al., 2016a). We measured two types of constraints. Specific constraints tied to the specific day of the survey, i.e. those constraints that could vary on a day-by-day basis. We included these constraints directly in the choice, as the stated choice experiment also is pivoted around the trip for which the constraints were collected, so any constraint on that day would be highly relevant for the departure time choice made in the stated choice experiment. Secondly, we also asked about their general work schedule, i.e. if they had fixed work hours, which are the same every day. Unlike the former, this captures a long term contractual agreement with the employer, and thus is likely to strengthen the manifestation of inertia. We utilized this information to define the overall (long term) inertia (explained in greater details in the next paragraph).

We envision inertia in departure time decisions to be related to individual commitments and constraints, such as family commitments within the household (e.g., if respondents have children and/or a partner) as well as long term work constraints. The reason why family commitment is expected to be relevant in this context is due to coordination among household members. Especially for households with children, having regular daily routines is important for everyday organization. In addition to that, we believe that general work conditions in terms of work hour start/finishing times is likely to impact the level of inertia with respect to departure time. Thus, to operationalize our model for inertia in the context of departure time choices we rely on socio-demographics (especially the ones relating to the household composition) and fixed work (start) hours.

\subsection{Modelling latent inertia}

Denote the latent inertia as $I$. The latent variable model consists of two components: a structural equation for the latent variable, and a set of $K$ measurement equations for each of its indicators, indexed by $k$. In our specification we assume that the habitual nature 


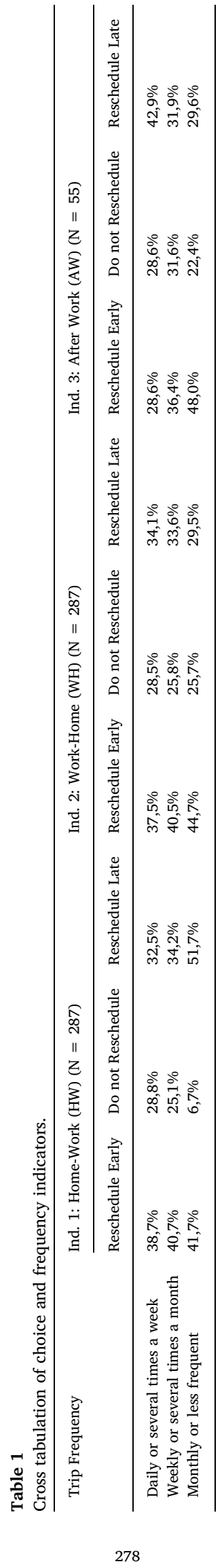




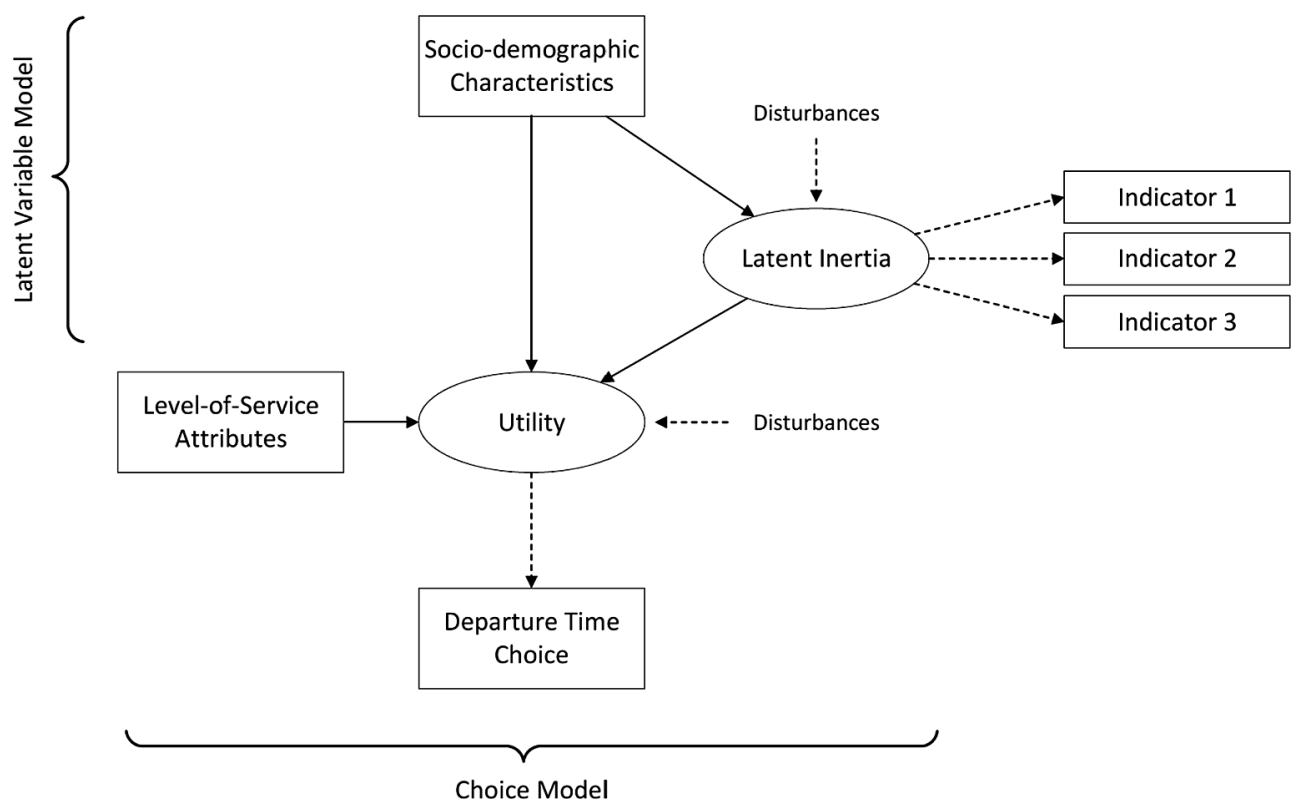

Fig. 5. Modelling framework of the Integrated Choice and Latent Variable (ICLV) model.

of inertia is revealed by three indicators, namely the self-reported frequency of the trips provided in the travel diary for journeys from (1) home to work (HW), (2) work to home (WH), and (3) in the evening after work (AW). Including indicators for different time periods throughout the day enables us to capture a broader inertia effect, to account for the fact that morning departure time choices are often scheduled in coordination with the remaining trips and activities during the day and potential constraints at that specific location. The structural equation and the measurement equations take the form:

$$
\begin{aligned}
& I_{n}=\alpha+\gamma_{Z} \cdot Z_{n}+\omega_{n} \\
& I n d_{n k}=\delta_{k}+\lambda_{k} \cdot I_{n}+\nu_{n k}
\end{aligned}
$$

where

- $I_{n}$ is the latent (unobservable) variable Inertia for individual $n$.

- $Z_{n}$ is a vector of explanatory observed covariates and $\gamma_{Z}$ is the corresponding vector of unknown coefficients to be estimated.

- Ind $d_{n k}$ is the indicator $k$ of the latent variable $I_{n}$ for individual $n$.

- $\lambda_{k}$ is a coefficient associated with $I_{n}$, i.e. the parameter for indicator $k$.

- $\alpha$ and $\delta_{k}$ are intercepts in the structural and measurement equations for the indicator $k$ respectively.

- $\omega_{n}$ is a normally distributed error term for the latent variable with zero mean and covariance matrices $\Sigma_{\omega}$.

- $v_{n k}$ are identically independently distributed (i.i.d.) error terms for the indicator of the measurement equations.

The latent variable is only known up to its distribution. Let $\phi$ be the standard normal distribution function. Assuming independence among the LV indicators (for simplicity), the distribution of the latent variable is:

$$
f\left(I_{n} \mid Z_{n} ; \alpha, \gamma_{Z}, \sigma_{\omega}\right)=\frac{1}{\sigma_{\omega}} \phi\left(\frac{I_{n}-\left(\alpha+\gamma_{Z} \cdot Z_{n}\right)}{\sigma_{\omega}}\right)
$$

Since the indicator responses are clearly ordered (and non-linear), we treat the responses as ordered choices and specify the indicator models as ordered logit models ${ }^{2}$, similar to Daly et at. (2012) and Valeri and Cherchi (2016). Thus, we model the probability that the inertia, $I$, lies within a range to give the observed response $I n d_{n k}=m$ defined by cut-off points $\tau_{k, m-1}$ and $\tau_{k, m}$ :

$$
P\left(\operatorname{Ind}_{n k}=m \mid I ; \delta_{k}, \lambda_{k}, \tau_{k, m}\right)=\Phi\left(\tau_{k, m}-\lambda_{k} I\right)-\Phi\left(\tau_{k, m-1}-\lambda_{k} I\right)
$$

where $\Phi$ is the cumulative density function, and $\tau_{k, m}$ are the threshold values for the intervals for indicator k. Due to the logistic distribution of the error term the probability takes the form of:

$$
P\left(\operatorname{Ind}_{n k}=m \mid I ; \delta_{k}, \lambda_{k}, \tau_{m, k}\right)=\left(\frac{1}{1+e^{\delta_{k}+\lambda_{k} \cdot I_{n}-\tau_{k, m}}}\right)-\left(\frac{1}{1+e^{\delta_{k}+\lambda_{k} \cdot I_{n}-\tau_{k, m-1}}}\right)
$$

\footnotetext{
${ }^{2}$ The logistic distribution was chosen for simplicity due to its closed cumulative form (i.e. we avoid excessive random sampling)
} 


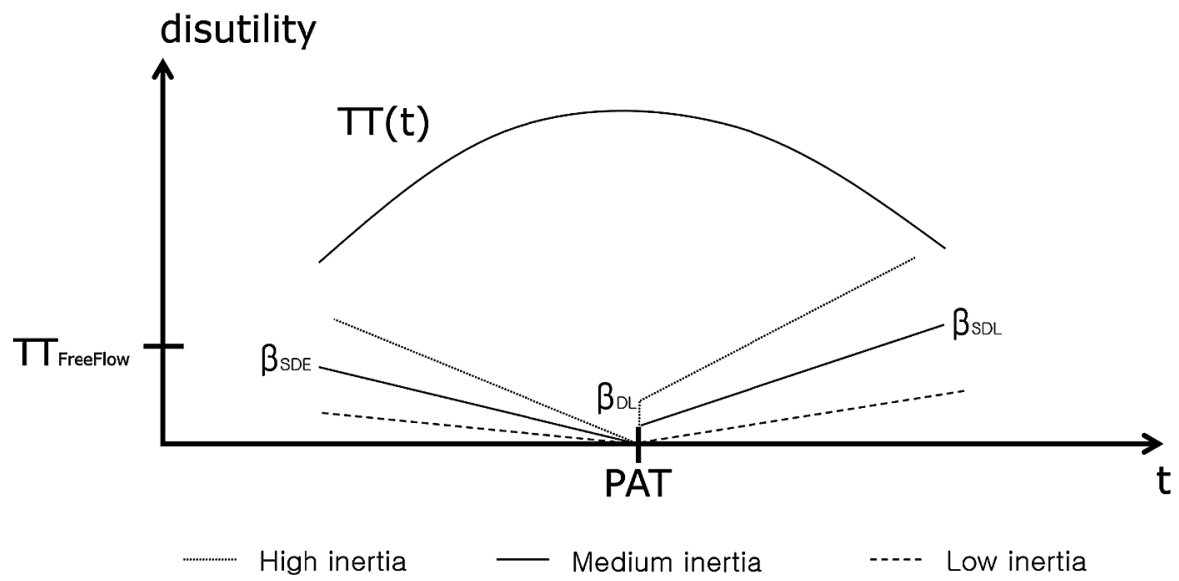

Fig. 6. Disutility as a function of arrival time (at work).

The latent variable spans from minus infinity to infinity. Since the three indicators $k$ are measured on a six-point scale $(\mathrm{M}=6)$ we have $\tau_{k, 0}=-\infty$ and $\tau_{k, 6}=\infty$. Given six-point indicators, we consider five intermediate cut-off points. If we normalize the intercept, then we can estimate all cut-off points except one. Thus, we normalize $\delta_{k}=0$ and $\tau_{k, 1}=0$ for identification and estimate the remaining four intermediate values. The actual model-specification then takes the form:

$$
\begin{gathered}
P\left(\operatorname{Ind}_{n k}=1\right)=\left(\frac{1}{1+e^{\lambda_{k} \cdot I_{n}-\tau_{k, 1}}}\right) \\
P\left(\text { Ind }_{n k}=2\right)=\left(\frac{1}{1+e^{\lambda_{k} \cdot I_{n}-\tau_{k, 2}}}\right)-\left(\frac{1}{1+e^{\lambda_{k} \cdot I_{n}-\tau_{k, 1}}}\right) \\
\vdots \\
P\left(\operatorname{Ind}_{n k}=6\right)=1-\left(\frac{1}{1+e^{\lambda_{k} \cdot I_{n}-\tau_{k, 5}}}\right)
\end{gathered}
$$

\subsection{Modelling departure time: Scheduling model}

For the departure time choice we rely on the Small's (1982) Scheduling Model (SM), which consists of a tradeoff between departure time and travel time. The model assumes that individuals have a Preferred Arrival Time (PAT), which is typically located during the peak hours, and changes away from PAT lead to rescheduling disutility, while the disutility for travel time is reduced. This tradeoff is depicted in Fig. 6, which showcases the disutility from travel time (TT) and three scheduling components: Scheduling Delay Early (SDE), Scheduling Delay Late (SDL), and a Discrete Lateness (DL) dummy. The marginal disutility of SDE and SDL is assumed to be linear, and the disutility for late arrival is typically greater than for early arrival (see, e.g., Arellana et al., 2012; de Jong et al., 2003; Thorhauge et al., 2016a), indicated by a steeper slope for SDL in the figure. Since inertia is expected to affect individuals' preferences to reschedule, its impact will increase the penalties of changing their departure times. In Fig. 6 this is represented through various slopes for SDE and SDL (but not restricted to only these slopes) for individuals with high inertia (dotted line), medium inertia (solid line), and low inertia (dashed line). Furthermore, the discrete lateness (DL) penalty is also assumed to be dependent on individuals' inertia, indicated in Fig. 6 as various vertical lines for different levels of inertia (using the same line styles as before).

In this paper we define the Scheduling Model similar to Thorhauge et al. (2017, 2016a). However, in our formulation, we assume that the preference for scheduling is different depending on the extent to which an individual has developed inertia. To capture this effect, the (systematic) utility to reschedule in Eq. (7) includes the interaction between the latent variable, $I_{n}$, and the scheduling preferences:

$$
V_{\text {intc }}=\alpha_{i}+\beta_{c}^{T C} T C_{i n t}+\beta_{c}^{E(T T)} E(T T)_{i n t}+\left(\beta_{c}^{E(S D E)} E(S D E)_{i n t}+\beta_{c}^{E(S D L)} E(S D L)_{i n t}+\beta_{c}^{D L} D L_{i n t}\right) \cdot I_{n}
$$

where $T C_{i n t}, E(T T)_{i n t}, E(S D E)_{i n t}, E(S D L)_{i n t}$, and $D L_{i n t}$ are the travel cost, expected travel time, expected scheduling delay early, expected scheduling delay late, and a discrete lateness dummy respectively for individual $n$, alternative $i$, and choice task $t$. In particular $\mathrm{E}(T T)$ was defined as the sum of the travel time weighted by the probability $\left(p_{q}\right)$ that each travel time occurs. Since the arrival time is dependent on the travel time, $E(S D E)$ and $E(S D L)$ are defined in the same way. Thus define $W=\{T T, S D E, S D L\}$ it is:

$$
E\left(W_{\text {int }}\right)=\sum_{q=1}^{Q} p_{q} \cdot Z_{\text {intq }}
$$

where $\sum_{q=1}^{Q} p_{q}=1$ and $S D E$ and $S D L$ are the difference between the arrival time and the preferred arrival time (PAT):

$$
S D E_{\text {intq }}=\max \left(-S D_{\text {intq }} ; 0\right)
$$




$$
\begin{aligned}
& S D L_{i n t q}=\max \left(0 ; S D_{\text {intq }}\right) \\
& S D_{\text {intq }}=D T_{\text {int }}+T T_{\text {intq }}-P A T_{n}
\end{aligned}
$$

Corresponding parameters to be estimated are $\beta_{c}^{T C}, \beta_{c}^{E(T T)}, \beta_{c}^{E(S D E)}, \beta_{c}^{E(S D L)}$, and $\beta_{c}^{D L}$, and $\alpha_{i}$ is the alternative-specific constant to be estimated. Furthermore, it is widely acknowledged that temporal constraints impact the preferences and (especially) penalties for late arrival (Asensio and Matas, 2008; Börjesson, 2008; de Jong et al., 2003; Hess et al., 2007; Lizana et al., 2013; Thorhauge et al., 2016a). Therefore, all $\beta_{c}$ are estimated specific for individuals who were flexible and individuals who had arrival time constraints at work.

Since the model is estimated based on SP-data with multiple observations per respondent, we specify an error term to account for correlation among those observations as commonly adopted in ICLV models. Thus, including the error terms we specify the full utility function including both the systematic and random part as follows:

$$
U_{\text {intc }}=V_{\text {intc }}+\sigma_{i} \eta_{n}+\varepsilon_{\text {int }}
$$

where the $\varepsilon_{i n t}$ are i.i.d. extreme value (EV) type 1 error terms, and the $\eta_{n}$ 's are $\operatorname{Normal}(0,1)$ distributed error components (EC) for each respondent $n$ capturing correlation between choice tasks for the same individual, $\sigma_{i}$ are corresponding parameters to be estimated. According to Walker et al. (2007) it is possible to estimate $\sigma_{i}$ for all alternatives, or (as we do in this case) estimate $\sigma_{i}$ for all alternatives except one, and estimate the correlation. More specifically, we normalize $\sigma_{2}=0$, and estimate the correlation $\left(\rho_{1,3}\right)$ between $\sigma_{1}$ and $\sigma_{3}$.

\subsection{Joint model estimation}

As in the typical hybrid choice models, the probability of individual $n$ choosing alternative $i$ in choice task $t$ is given by:

$$
P\left(Y_{i n t} \mid X_{i n t} ; \alpha_{i}, \beta, \sigma_{i}\right)=\int \frac{\exp \left(V_{i n t}+\sigma_{i} \eta_{i n}\right)}{\sum_{j=1}^{J} \exp \left(V_{j n t}+\sigma_{j} \eta_{j n}\right)} f(\eta) d \eta, \quad \forall i, j \in C_{n}
$$

The joint probability of the Integrated Choice and Latent Variable (ICLV) model is given by the product of the probability of choice model and the probability of the latent variable model. The unconditional joint probability is the integral of the conditional probability over the distribution of $\omega_{k n}$ and $\eta_{i n}$ :

$$
\begin{gathered}
P\left(Y_{\text {int }}, I_{n d} \mid X_{i n t}, Z_{n}, I_{n} ; \alpha_{i}, \beta, \sigma_{i}, \delta_{k}, \lambda_{k}, \tau_{k, m}, \alpha, \gamma_{Z}, \sigma_{\omega}\right)=\int_{I} \prod_{t=1}^{T} P\left(Y_{i n t} \mid X_{i n t} ; \alpha_{i}, \beta, \sigma_{i}\right) \prod_{k=1}^{K} P\left(I n d_{n k} \mid I ; \delta_{k}, \lambda_{k}, \tau_{k, m}\right) \\
f\left(I_{n} \mid Z_{n} ; \alpha, \gamma_{Z}, \sigma_{\omega}\right) d I
\end{gathered}
$$

The log-likelihood function then is given by the logarithm of probability across all individuals and alternatives:

$$
L L=\sum_{n} \sum_{i} y_{i n t} \ln \left[P\left(Y_{i n t}, I_{n d} \mid X_{i n t}, Z_{n}, I_{n} ; \alpha_{i}, \beta, \sigma_{i}, \delta_{k}, \lambda_{k}, \tau_{m, k}, \alpha, \gamma_{Z}, \sigma_{\omega}\right)\right]
$$

where $y_{\text {int }}$ is 1 if alternative $i$ is chosen for individual $n$ and choice task $t, 0$ otherwise.

\section{Results}

\subsection{Modelling estimates}

The final model is estimated on 2525 observations gathered from 287 individuals. The estimation was done using the CFSQP (Lawrence et al., 1997) algorithm in PythonBiogeme 2.6 (Bierlaire, 2016). Table 2 presents the parameter estimates for a base ML model (M1) without inertia as well as the ICLV model (M2) including inertia. Furthermore, Table 3 compares the willingness to pay and marginal rates of substitution from the two models, while Table 4 presents direct and cross elasticities.

As seen in Table 2, we estimated different Level-of-Service parameters (except for travel cost) for individuals with and without arrival time constraints at work. We found the parameters to be significantly different for all Level-of-Service attributes, except for E (SDE), which was then specified as a generic parameter for the full sample. Furthermore, we note that in both models all parameters for the Level-of-Service attributes are highly significant (at minimum 99\% confidence) and negative as expected, with the exception of the discrete lateness dummy for individuals who did not have constraints at work, which is expected considering that the arrival time for those individuals are more flexible in nature. We also tested various non-linear effects for the scheduling components (square, log, power, and box-cox functions) but were not able to reject the linearity hypothesis. From Table 3 we note that due to the interaction between Level-of-Service attributes and Inertia the (average) willingness to pay for (a reduction in) early and late arrival is higher in the ICLV model compared to the ML model. Similarly, the marginal rate of substitution with travel time shows a similar effect for the early and late arrival, i.e., individuals are willing to sacrifice more travel time to reduce rescheduling. We also note that the ratio between late and early arrival in both models is about 2, making the average disutility from late arrival twice as large as early arrival. Table 3 also shows that the WTP for (a reduction in) travel time is higher (in both models) than the WTP for early and late arrival respectively. This is in line with some studies (e.g., de Jong, 2003 and Hess et al., 2007), while other studies have found the opposite (e.g. Peer et al., 2014). In our case, we believe this is a result of the characteristics of the sample, which mainly consists 
Table 2

Final parameter estimates of the Integrated Choice and Latent Variable (ICLV) model.

\begin{tabular}{|c|c|c|c|c|c|c|}
\hline & \multicolumn{3}{|c|}{ M1: ML model without inertia } & \multicolumn{3}{|c|}{ M2: ICLV model with inertia } \\
\hline & Value & $t$-test & $\mathrm{p}$-value & Value & $t$-test & p-value \\
\hline \multicolumn{7}{|l|}{ Choice model } \\
\hline ASC, early departure & -0.752 & -1.220 & 0.220 & -0.220 & -0.260 & 0.790 \\
\hline ASC, late departure & -0.164 & -0.370 & 0.710 & 0.216 & 0.300 & 0.760 \\
\hline Travel Cost & -0.137 & -5.400 & 0.000 & -0.121 & -3.530 & 0.000 \\
\hline Travel Time * Constraints & -0.125 & -3.190 & 0.000 & -0.120 & -2.460 & 0.010 \\
\hline Travel Time * No Constraints & -0.196 & -5.400 & 0.000 & -0.189 & -4.270 & 0.000 \\
\hline $\mathrm{E}(\mathrm{SDE})$ & -0.041 & -4.950 & 0.000 & & & \\
\hline $\mathrm{E}(\mathrm{SDL}) *$ Constraints & -0.103 & -8.310 & 0.000 & & & \\
\hline $\mathrm{E}(\mathrm{SDL}) *$ No Constraints & -0.070 & -7.540 & 0.000 & & & \\
\hline $\mathrm{DL} *$ Constraints & -0.627 & -2.990 & 0.000 & & & \\
\hline $\mathrm{E}(\mathrm{SDE}) *$ Inertia & & & & -0.021 & -3.600 & 0.000 \\
\hline $\mathrm{E}(\mathrm{SDL}) *$ Inertia * Constraints & & & & -0.048 & -4.300 & 0.000 \\
\hline $\mathrm{E}(\mathrm{SDL}) *$ Inertia * No Constraints & & & & -0.032 & -4.450 & 0.000 \\
\hline DL * Inertia * Constraints & & & & -0.522 & -2.220 & 0.030 \\
\hline Std. Dev., early dep. time & -2.320 & -12.750 & 0.000 & 2.310 & 12.000 & 0.000 \\
\hline Std. Dev., late dep. time & 2.540 & 12.380 & 0.000 & 2.510 & 12.140 & 0.000 \\
\hline Correlation, early-late & 1.540 & 5.410 & 0.000 & 1.380 & 5.000 & 0.000 \\
\hline \multicolumn{7}{|l|}{ Latent variable structural equation } \\
\hline Intercept & & & & 2.050 & 5.840 & 0.000 \\
\hline Male & & & & 0.582 & 2.510 & 0.010 \\
\hline Has Children * Female & & & & 0.373 & 1.510 & 0.130 \\
\hline Fixed work Hours & & & & 0.738 & 3.400 & 0.000 \\
\hline \multicolumn{7}{|l|}{ Latent variable measurement equations } \\
\hline \multicolumn{7}{|l|}{ Indicator 1: Home-Work (HW) } \\
\hline$\lambda_{1}$ & & & & 1.970 & 7.150 & 0.000 \\
\hline$\tau_{1,2}$ & & & & 0.150 & 0.950 & 0.340 \\
\hline$\tau_{1,3}$ & & & & 0.410 & 1.550 & 0.120 \\
\hline$\tau_{1,4}$ & & & & 1.140 & 2.610 & 0.010 \\
\hline$\tau_{1,5}$ & & & & 3.850 & 5.240 & 0.000 \\
\hline \multicolumn{7}{|l|}{ Indicator 2: Work-Home (WH) } \\
\hline$\lambda_{2}$ & & & & 1.200 & 8.090 & 0.000 \\
\hline$\tau_{2,2}$ & & & & 0.507 & 3.200 & 0.000 \\
\hline$\tau_{2,3}$ & & & & 0.993 & 5.100 & 0.000 \\
\hline$\tau_{2,4}$ & & & & 1.570 & 6.990 & 0.000 \\
\hline$\tau_{2,5}$ & & & & 3.020 & 9.780 & 0.000 \\
\hline \multicolumn{7}{|l|}{ Indicator 3: After Work (AW) } \\
\hline$\lambda_{3}$ & & & & 0.521 & 3.970 & 0.000 \\
\hline$\tau_{3,2}$ & & & & 0.293 & 1.720 & 0.090 \\
\hline$\tau_{3,3}$ & & & & 0.550 & 2.490 & 0.010 \\
\hline$\tau_{3,4}$ & & & & 1.790 & 5.090 & 0.000 \\
\hline$\tau_{3,5}$ & & & & 4.090 & 6.210 & 0.000 \\
\hline \multicolumn{7}{|l|}{ Model summary } \\
\hline Final log likelihood for the choice model: & -1812.494 & & & -1766.157 & & \\
\hline Parameters in the choice model & 12 & & & 12 & & \\
\hline AIC for the choice model & 3600.988 & & & 3508.314 & & \\
\hline BIC for the choice model & 3718.996 & & & 3626.322 & & \\
\hline Final log likelihood for the ICLV model: & N/A & & & -2477.392 & & \\
\hline Parameters in the ICLV model & $\mathrm{N} / \mathrm{A}$ & & & 31 & & \\
\hline AIC for the ICLV model & N/A & & & 4892.784 & & \\
\hline BIC for the ICLV model & N/A & & & 5197.638 & & \\
\hline
\end{tabular}

of highly skilled workers (many were university employees). We found those individuals to work (on average) more hours per week ( $43.5 \mathrm{~h}$ per week for men, and $40.8 \mathrm{~h}$ per week for women) than the typical work week (which in Denmark is $37 \mathrm{~h}$ per week). Thus, we suspect individuals in our sample to value (in general) travel time saving more than reducing their scheduling, possibly because a reduction in their travel time will "free up time", which can be utilized to do other things.

Focusing explicitly on the impact of accounting for inertia in the ICLV model, we note that the marginal disutility of rescheduling increases as inertia increases. We found this to be the case for both early and late arrival as well as the discrete lateness penalty. This means that individuals who have repeated the same behavior on a regular basis in the past will have a lower probability of rescheduling their departure time. This supports our first hypothesis (H1). We will return to the discussion of how the level of inertia impacts individual behavior and dive deeper into this analysis in Sections 4.2 and 4.3.

In line with our second hypothesis (H2) we identified some systematic characteristics of inertia. We tested a wide range of 
Table 3

Willingness to pay and marginal rate of substitution. $95 \%$ confidence intervals in brackets.

\begin{tabular}{lll}
\hline & M1: SM model (without inertia) & M2: ICLV model (with inertia) \\
\hline Willingness to pay [DKK/min] & & 1.23 \\
$\frac{\partial U}{\partial E(T T)} / \frac{\partial U}{\partial T C}$ & 1.17 & $(0.78 ; 1.91)$ \\
$\frac{\partial U}{\partial E(S D E)} / \frac{\partial U}{\partial T C}$ & $(0.80 ; 1.54)$ & 0.37 \\
$\frac{\partial U}{\partial E(S D L)} / \frac{\partial U}{\partial T C}$ & 0.30 & $0.16 ; 1.18)$ \\
$\frac{\partial U}{\partial D L} / \frac{\partial U}{\partial T C}$ & $(0.15 ; 0.59)$ & 0.79 \\
Marginal rate of substitution & 0.62 & $(0.36 ; 2.13)$ \\
$\frac{\partial U}{\partial E(S D E)} / \frac{\partial U}{\partial E(T T)}$ & $(0.42 ; 1.01)$ & 2.00 \\
$\frac{\partial U}{\partial E(S D L)} / \frac{\partial U}{\partial E(T T)}$ & 2.21 & $(0.36 ; 4.77)$ \\
$\frac{\partial U}{\partial D L} / \frac{\partial U}{\partial E(T T)}$ & $(0.81 ; 4.07)$ & 0.30 \\
$\frac{\partial U}{\partial E(S D L)} / \frac{\partial U}{\partial E(S D E)}$ & & $(0.12 ; 1.32)$ \\
$\frac{\partial U}{\partial D L} / \frac{\partial U}{\partial E(S D E)}$ & 0.27 & 0.65 \\
$\frac{\partial U}{\partial D L} / \frac{\partial U}{\partial E(S D L)}$ & $(0.13 ; 0.69)$ & $(0.29 ; 2.87)$ \\
& 0.58 & 1.70 \\
& $(0.36 ; 1.40)$ & $(0.34 ; 7.39)$ \\
& 2.44 & 1.99 \\
& $(0.80 ; 6.76)$ & $(1.25 ; 3.17)$ \\
& 2.06 & 3.84 \\
& $(1.30 ; 3.48)$ & $(-4.45 ; 23.28)$
\end{tabular}

Table 4

Direct and cross elasticities for Level-of-Service attributes (such as travel time and cost, etc.) 95\% confidence intervals in brackets.

\begin{tabular}{|c|c|c|c|c|c|c|c|}
\hline \multirow[b]{2}{*}{ Alternative } & & \multicolumn{3}{|c|}{ M1: SM model (without inertia) } & \multicolumn{3}{|c|}{ M2: ICLV model (with inertia) } \\
\hline & & Alt 1: Early & Alt 2: Current & Alt 3: Late & Alt 1: Early & Alt 2: Current & Alt 3: Late \\
\hline \multirow[t]{3}{*}{ Travel Cost } & Alt 1: Early & $\begin{array}{l}-0.95 \\
(-1.28 \\
-0.62)\end{array}$ & $\begin{array}{l}0.60 \\
(0.39 ; 0.79)\end{array}$ & $\begin{array}{l}0.60 \\
(0.39 ; 0.80)\end{array}$ & $\begin{array}{l}-0.83 \\
(-1.23 \\
-0.39)\end{array}$ & $\begin{array}{l}0.51 \\
(0.25 ; 0.78)\end{array}$ & $\begin{array}{l}0.52 \\
(0.26 ; 0.78)\end{array}$ \\
\hline & Alt 2: Current & $\begin{array}{l}0.52 \\
(0.31 ; 0.77)\end{array}$ & $\begin{array}{l}-2.25 \\
(-2.93 \\
-1.52)\end{array}$ & $\begin{array}{l}0.52 \\
(0.32 ; 0.79)\end{array}$ & $\begin{array}{l}0.44 \\
(0.19 ; 0.72)\end{array}$ & $\begin{array}{l}-1.93 \\
(-2.86 \\
-0.98)\end{array}$ & $\begin{array}{l}0.40 \\
(0.18 ; 0.69)\end{array}$ \\
\hline & Alt 3: Late & $\begin{array}{l}0.50 \\
(0.31 ; 0.68)\end{array}$ & $\begin{array}{l}0.50 \\
(0.32 ; 0.69)\end{array}$ & $\begin{array}{l}-1.05 \\
(-1.40 \\
-0.71)\end{array}$ & $\begin{array}{l}0.44 \\
(0.21 ; 0.67)\end{array}$ & $\begin{array}{l}0.42 \\
(0.21 ; 0.66)\end{array}$ & $\begin{array}{l}-0.87 \\
(-1.30 ;-0.43)\end{array}$ \\
\hline \multirow[t]{3}{*}{ Expected Travel Time } & Alt 1: Early & $\begin{array}{l}-2.62 \\
(-3.67 \\
-1.56)\end{array}$ & $\begin{array}{l}1.97 \\
(1.11 ; 2.80)\end{array}$ & $\begin{array}{l}1.97 \\
(1.11 ; 2.81)\end{array}$ & $\begin{array}{l}-2.48 \\
(-3.75 \\
-1.16)\end{array}$ & $\begin{array}{l}1.84 \\
(0.83 ; 2.89)\end{array}$ & $\begin{array}{l}1.83 \\
(0.81 ; 2.84)\end{array}$ \\
\hline & Alt 2: Current & $\begin{array}{l}0.93 \\
(0.50 ; 1.42)\end{array}$ & $\begin{array}{l}-4.72 \\
(-6.55 \\
-2.80)\end{array}$ & $\begin{array}{l}0.93 \\
(0.51 ; 1.46)\end{array}$ & $\begin{array}{l}0.86 \\
(0.32 ; 1.39)\end{array}$ & $\begin{array}{l}-4.40 \\
(-6.73 \\
-2.12)\end{array}$ & $\begin{array}{l}0.79 \\
(0.31 ; 1.34)\end{array}$ \\
\hline & Alt 3: Late & $\begin{array}{l}1.80 \\
(1.05 ; 2.56)\end{array}$ & $\begin{array}{l}1.80 \\
(1.06 ; 2.59)\end{array}$ & $\begin{array}{l}-2.79 \\
(-3.94 \\
-1.64)\end{array}$ & $\begin{array}{l}1.72 \\
(0.83 ; 2.63)\end{array}$ & $\begin{array}{l}1.68 \\
(0.84 ; 2.63)\end{array}$ & $\begin{array}{l}-2.53 \\
(-3.92 ;-1.13)\end{array}$ \\
\hline $\begin{array}{l}\text { Expected Scheduling Delay } \\
\text { Early }\end{array}$ & Alt 1: Early & $\begin{array}{l}-0.96 \\
(-1.30 \\
-0.60)\end{array}$ & $\begin{array}{l}0.46 \\
(0.28 ; 0.64)\end{array}$ & $\begin{array}{l}0.46 \\
(0.28 ; 0.64)\end{array}$ & $\begin{array}{l}-1.04 \\
(-1.31 \\
-0.62)\end{array}$ & $\begin{array}{l}0.61 \\
(0.33 ; 0.84)\end{array}$ & $\begin{array}{l}0.43 \\
(0.24 ; 0.60)\end{array}$ \\
\hline $\begin{array}{l}\text { Expected Scheduling Delay } \\
\text { Late }\end{array}$ & Alt 3: Late & $\begin{array}{l}0.42 \\
(0.30 ; 0.54)\end{array}$ & $\begin{array}{l}0.42 \\
(0.31 ; 0.55)\end{array}$ & $\begin{array}{l}-1.77 \\
(-2.20 \\
-1.35)\end{array}$ & $\begin{array}{l}0.42 \\
(0.27 ; 0.55)\end{array}$ & $\begin{array}{l}0.49 \\
(0.32 ; 0.66)\end{array}$ & $\begin{array}{l}-1.38 \\
(-1.72 ;-0.92)\end{array}$ \\
\hline
\end{tabular}

explanatory variables. The final vector Z (eq. (1)) of explanatory variables consists of males, fixed work hours, and females interacted with having children. More specifically, we found that in our sample inertia increases for respondents who are male, have children interacted with being females, and have fixed work hours, and thereby are constrained in their arrival time at work. We note however, that the parameter for children interacted with females is only significant at about $85 \%$ confidence, but we have tested the model using responses from individuals outside of the study area, and found the significance level of the parameter to increase, so we believe that this is simply a matter of having access to a larger dataset to obtain a more robust parameter estimate.

We included the fixed work hours as an explanatory variable for the latent inertial behavior, since this reveals an ongoing tendency in behavior, while we included the temporal constraints for that day (e.g., meetings, etc.) directly in the choice model as an 
explanatory variable for the departure time decision on that specific day. The fixed work hours (as opposed to the temporal constraint included in the choice model) is a contractual requirement by one's employer, while the temporal constraint is tied specifically to the trip diary for that specific day of the survey. In other words, an individual with flexible working hours might be constrained on that specific day, which will impact the choice on that day (but probably having little effect on the long-term inertia).

We believe that the fact that males are more likely to be more inertial could be due to women performing more activities and in general having more complex (and likely, less predefined) schedules with a higher degree of ad-hoc and spontaneous activities than their male counterparts. The fact that inertial behavior is positively influenced by the presence of children is in line with our expectations and the existing literature, as the presence of children requires more organized daily family routines (Spagnola and Fiese, 2007). We found this effect to be more significant when interacting children with females. We believe this is due to women, to a larger extent, performing many of the daily tasks around escorting kids to and from daycare, school and leisure activities (see, e.g., Cerrato and Cifre, 2018; Starrels, 1994). Our data revealed that women work less than men (although in our sample both men and women on average work more than $37 \mathrm{~h}$ per week, which is the norm in Denmark), so we also tried to control for this effect as it might be relevant with respect to who is taking care of household tasks, but we found it not to be significant. Furthermore, we also tested if inertia was affected by individuals' age, but found this not to be significant. We believe that this is probably due to the inclusion of the presence of children in the household, which is likely a stronger determinant for inertia and also indirectly captures in which phase of their life respondents currently are (with or without children in the household). Finally, we also tested the sociodemographics directly in the choice model, but found these to only be significant through the latent variable.

\subsection{Segmentation of sample and their indicator response}

In order to highlight and compare the differences between "inertial" individuals and "non-inertial" individuals, we segment the sample based on their level of inertia. More specifically, using the latent variable Inertia, we split the sample into tertiles comprised of the top third, the middle third and the bottom third. The top third consists of the most inertial individuals, while the bottom third include the least inertial individuals. The middle third is (by definition) centered on the median, and consists of semi-inertial individuals.

The (numerical) value of the latent level inertia can only be interpreted by its impact on the indicators. Thus, Fig. 7 presents the predicted mean value for all three indicators for each of the three segments. For comparison we also included the score for the full sample (i.e. black bars). As expected, the figure confirms that the top third most inertial respondents (i.e. grey bars) have the highest predicted mean scores on all three indicators (recall higher score indicate a more frequent occurrence of the observed behavior). More specifically, we see that the reported morning commute is basically repeated every day for this segment, which means that the departure does not vary from day to day, while for the least inertial respondents the average predicted outcome of indicator 1 lies between 4 ("once a week") and 5 ("several times a week"). Furthermore, in line with Fig. 3 we note that the morning commute is by far the most inertial period of the day, while the afternoon commute back home is to a lesser extent inertial, likely because individuals use the time after work to take care of various errands, such as doing grocery shopping, etc., or meeting up with friends. Finally, frequency of activities carried out in the evenings seems (on average) to occur very rarely for all segments.

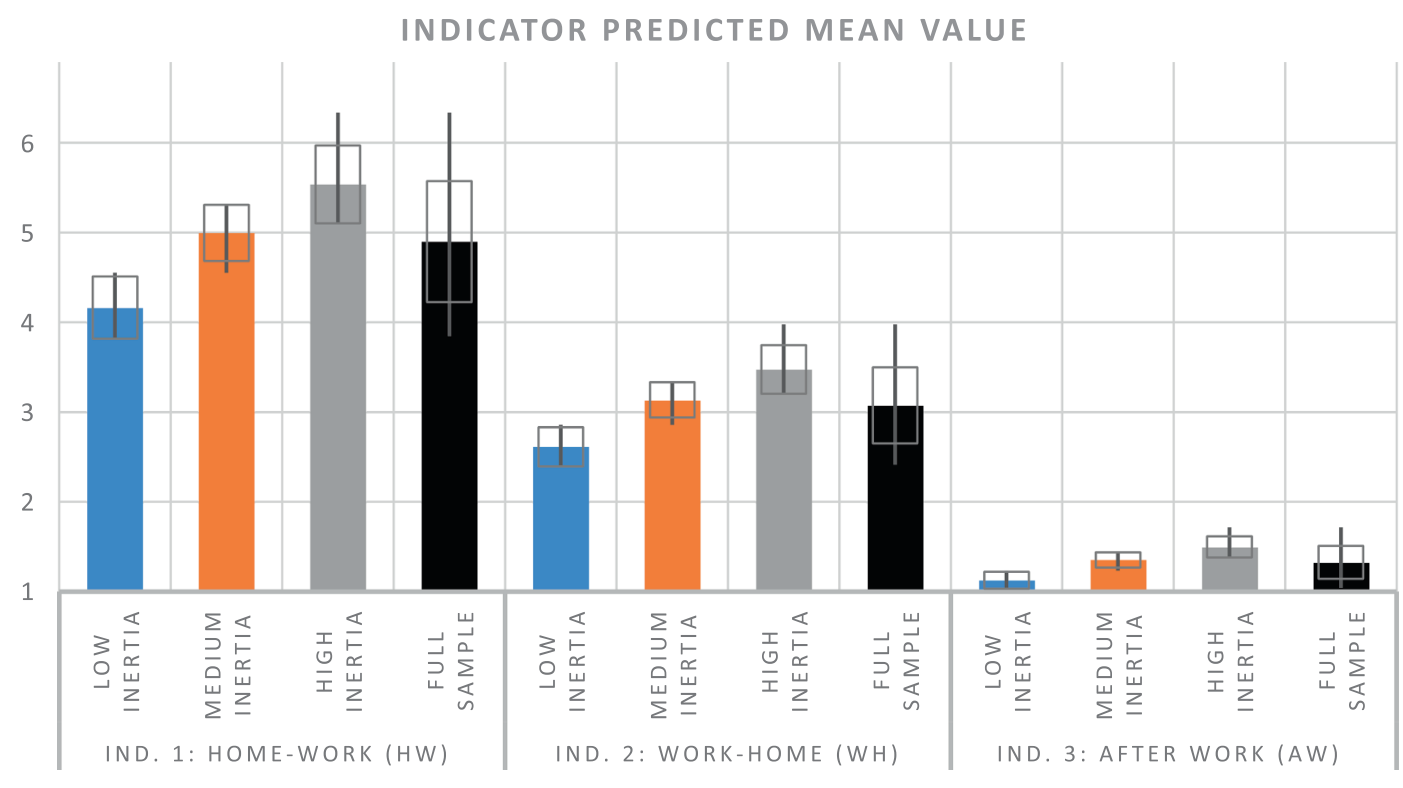

COLUMN: MEAN VALUE, BOX: STD. DEV, VERTICAL LINE: MINIMUM - MAXIMUM

Fig. 7. The predicted mean value for each for the three indicators. 
Table 5

Segment specific willingness to pay and marginal rate of substitution. 95\% confidence intervals in brackets.

\begin{tabular}{|c|c|c|c|}
\hline & Segment 1: Low inertia & Segment 2: Medium inertia & Segment 3: High inertia \\
\hline \multicolumn{4}{|c|}{ Willingness to pay $[\mathrm{DKK} / \mathrm{min}]$} \\
\hline$\partial U$ & 1.24 & 1.23 & 1.22 \\
\hline$\partial E(T T)^{\prime} \partial T C$ & $(0.76 ; 1.91)$ & $(0.84 ; 1.99)$ & $(0.72 ; 1.84)$ \\
\hline$\frac{\partial U}{\partial E(S D E)} / \frac{\partial U}{\partial T C}$ & $\begin{array}{l}0.30 \\
(0.14 ; 0.97)\end{array}$ & $\begin{array}{l}0.38 \\
(0.16 ; 1.22)\end{array}$ & $\begin{array}{l}0.43 \\
(0.18 ; 1.36)\end{array}$ \\
\hline$\frac{\partial U}{\partial U} / \frac{\partial U}{1}$ & 0.63 & 0.80 & 0.93 \\
\hline$\overline{\partial E(S D L)} / \overline{\partial T C}$ & $(0.29 ; 1.73)$ & $(0.37 ; 2.12)$ & $(0.43 ; 2.55)$ \\
\hline$\frac{\partial U}{\partial D L} / \frac{\partial U}{\partial T C}$ & $\begin{array}{l}1.33 \\
(0.27 ; 4.51)\end{array}$ & $\begin{array}{l}1.96 \\
(0.35 ; 4.15)\end{array}$ & $\begin{array}{l}2.72 \\
(0.47 ; 5.65)\end{array}$ \\
\hline \multicolumn{4}{|c|}{ Marginal rate of substitution } \\
\hline$\frac{\partial U}{\partial E(S D E)} / \frac{\partial U}{\partial E(T T)}$ & $\begin{array}{l}0.25 \\
(0.11 \cdot 103)\end{array}$ & 0.31 & $\begin{array}{l}0.35 \\
(0.14 \cdot 170)\end{array}$ \\
\hline$\partial U / \partial U$ & 0.52 & 0.66 & 0.77 \\
\hline$\overline{\partial E(S D L)} / \overline{\partial E(T T)}$ & $(0.25 ; 2.27)$ & $(0.28 ; 2.60)$ & $(0.35 ; 3.73)$ \\
\hline$\partial U / \partial U$ & 1.14 & 1.67 & 2.31 \\
\hline$\overline{\partial D L} / \frac{\partial E(T T)}{\partial-1}$ & $(0.32 ; 7.02)$ & $(0.29 ; 6.41)$ & $(0.40 ; 8.72)$ \\
\hline$\partial U$ & 1.88 & 2.01 & 2.09 \\
\hline$\overline{\partial E(S D L)} / \overline{\partial E(S D E)}$ & $(1.19 ; 3.11)$ & $(1.24 ; 3.12)$ & $(1.32 ; 3.29)$ \\
\hline$\frac{\partial U}{\partial} / \partial U$ & 2.74 & 3.80 & 5.00 \\
\hline$\overline{\partial D L} / \overline{\partial E(S D E)}$ & $(-11.71 ; 33.60)$ & $(-1.43 ; 17.99)$ & $(-0.17 ; 18.19)$ \\
\hline$\frac{\partial U}{U} / \frac{\partial U}{-}$ & 0.93 & 1.34 & 1.87 \\
\hline$\overline{\partial D L} / \overline{\partial E(S D L)}$ & $(-4.73 ; 12.65)$ & $(-0.62 ; 6.84)$ & $(-0.06 ; 7.15)$ \\
\hline
\end{tabular}

To get an even deeper understanding of the differences across segments, we also computed the segment specific willingness to pay and marginal rate of substitution (Table 5) as well as the average direct and cross elasticities (Table 6). In line with our expectations, Table 5 shows that the value of early and late arrival is higher for individuals who are most inertial, and lowest for individuals who are least inertial. Looking at the marginal rate of substitution between the rescheduling components and the travel time we see a similar trend. More specifically, on average $1 \mathrm{~min}$ of travel time corresponds to approximately 1.9 min of late arrival for the least inertial individuals, $1.5 \mathrm{~min}$ for semi inertial individuals, and only $1.3 \mathrm{~min}$ for the most inertial individuals. Similarly, $1 \mathrm{~min}$ of travel time correspond to approximately 4.0, 3.2, and $2.8 \mathrm{~min}$ of early arrival for individuals who are least, semi and most inertial respectively. Interestingly, the marginal rate of substitution between early and late arrival is almost the same across the three segments, indicating that the ratio between the penalty for early and late arrival is close to identical across the entire sample, but inertial individuals just factor the penalties for rescheduling (in both directions) the most. This fits well with our first hypothesis (H1).

\subsection{Policy Scenario: Toll ring}

To showcase the impact of our results in a policy analysis we use them to forecast the changes in demand for a relevant policy scenario which has been debated for the previous decade in Denmark (and Copenhagen in particular). This policy involves the implementation of congestion charging through the construction of a toll ring around Copenhagen. We defined pricing schemes similar to what exists in other Scandinavian cities (Fjellinjen, 2015; Transportstyrelsen, 2015a, 2015b), i.e., before 7:00 am and after 9:00 am the cost of entering Copenhagen is set to $10 \mathrm{DKK}$ (approximately $1.34 €$ ), with incremental cost of 3 DKK (approx. $0.40 €$ ) per 15 min going closer to the maximum cost of 22 DKK (approx. 2.95 €) between 7:45-8:15.

For sake of simplicity we assume that individuals do not change mode and that travel times in the different time slots are constant. This is of course not a perfectly realistic assumption, because the introduction of a toll ring scenario is likely to push some individuals into changing mode, but it does not diminish the validity of this discussion and of the results obtained. In addition, as individuals change time slot (or mode) this will influence the congestion level, causing the demand to adjust until a new system equilibrium is reached. However, modelling such effects would require a full demand and traffic assignment which is beyond the scope of this paper. This policy analysis should be considered for illustrative purposes only.

Fig. 8 shows the substitution patterns as a consequence of constructing a toll ring around Copenhagen for both the ICLV model and the base Scheduling Model (without inertia). For the ICLV we present both the overall substitution patterns for the full sample as well as the substitution patterns for three different segments of the sample with different levels of inertia. In line with our third hypothesis (H3), we see that the segment which is most inertial (grey bars) is the one least likely to reschedule, while the segment who is least inertial (blue bars) is the one most likely to reschedule. Interestingly, we also note that there seems to be a significant different between the overall substitution patterns between the model with and without inertia. More specifically, the base model without inertia predicts greater substitution, while accounting for the effect of inertia leads to a dampening of the willingness to reschedule. 


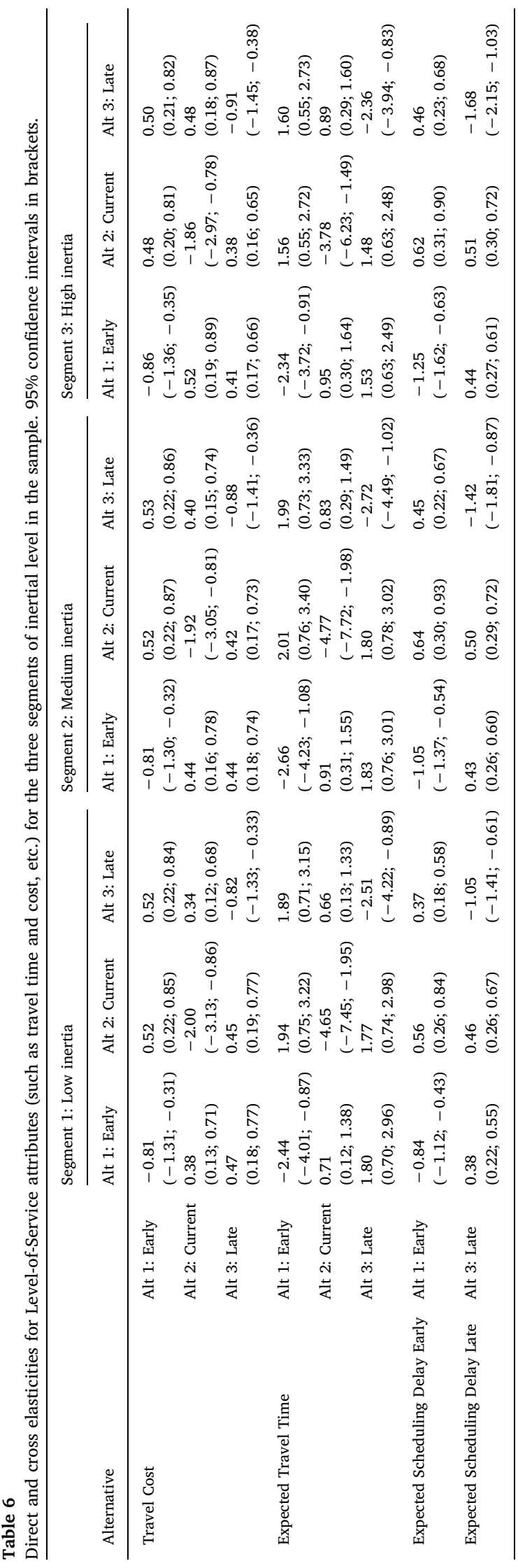




\title{
SUBSTITUTION PATTERN FOR A TOLL RING SCENARIO
}

\author{
ILOW INERTIA MMEDIUM INERTIA HIGH INERTIA \\ -FULL SAMPLE (ICLV MODEL) \#BASE MODEL WITHOUT HABIT
}

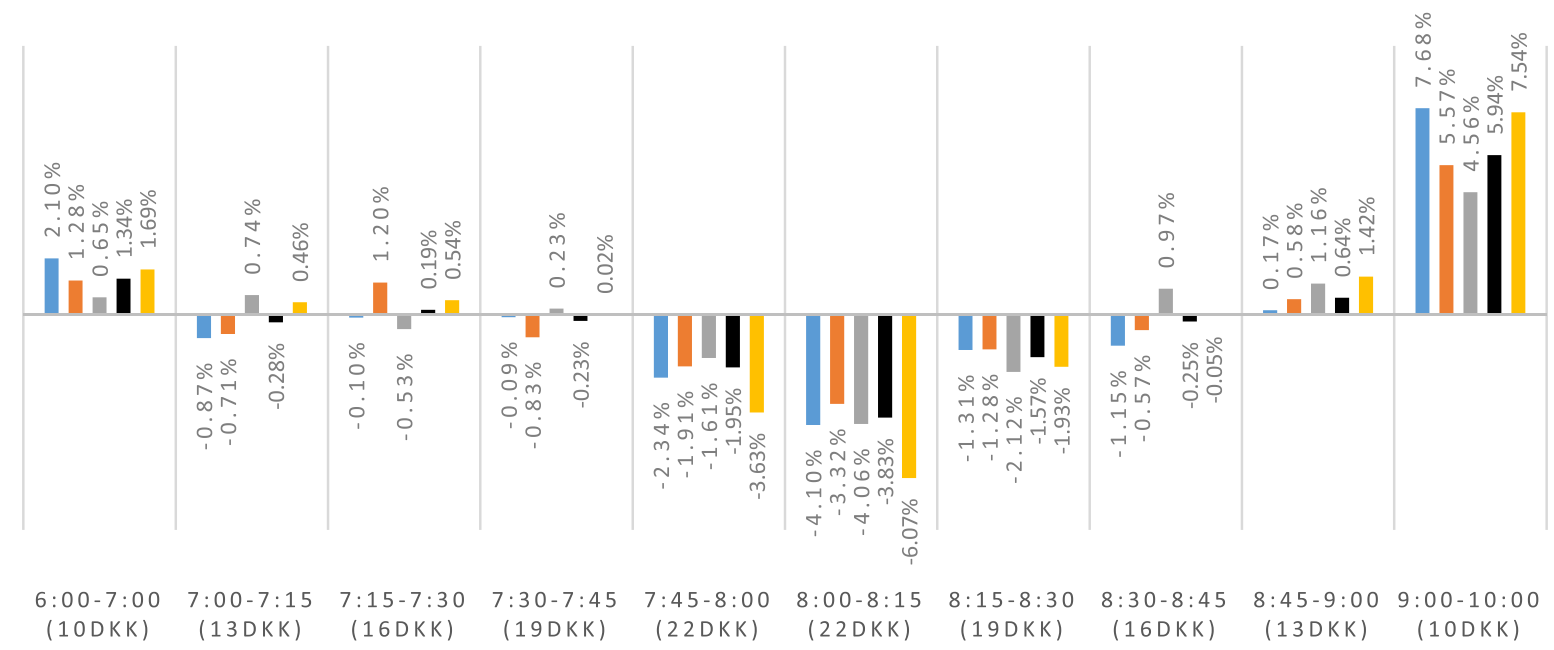

Fig. 8. Substitution patterns as a reaction to the introduction of a toll ring around Copenhagen.

\section{Discussion and conclusion}

In this paper we explored the impact of inertia in departure time choice. We hypothesized that (1) inertia affects departure time and rescheduling preferences, (2) socio-demographic characteristics can capture heterogeneity in inertia, and (3) this has policy implications when forecasting traffic demand strategies.

We found that inertia impacted not only the choice, but also the rescheduling preferences, i.e., inertial individuals are less likely to reschedule than non-inertial individuals, which confirms our first hypothesis. Furthermore we found that inertial behavior related to departure time is positively influenced by being male, having children interacted with being female and, finally, having fixed work hours, thereby confirming our second hypothesis. Finally, we tested policy implications of forecasting with/without inertia. More specifically, we defined a toll ring scenario as a countermeasure against congestion. We found that non-inertial individuals are most likely to reschedule, while inertial individuals are least likely to reschedule their departure. Furthermore, we compared the forecasting results to a model without inertia and found that the model without inertia predicts a greater willingness to shift departure time and thereby greater substitution patterns compared to the model with inertia. This shows that inertia indeed has forecasting implications for traffic demand policies, which confirms our third hypothesis.

The conclusion of this paper is that past behavior with respect to departure time decisions indeed impacts future departure time decisions, which is also in line with existing literature in other domains. It is difficult to say with certainty if the recurring behavior is due to habit or (other causes that lead to) inertia. To the extent possible with our data, we accounted for the effect of working constraints, which contribute to the strength of inertia, and showed that having (generally) fixed work hours (which do not vary on a day-to-day basis) is positively correlated with inertia. For those individuals the inertial behavior is likely to be driven (to a large extend) by external (work) constraints. We would like to point out that approximately $2 / 3$ of our sample have flexible work hours, hence an inertial behavior is (for the majority of the sample) not driven by having fixed work start times (on a regular basis), and therefore likely to indeed represent the underlying habitual behavior.

The model results in this study are based on a stated preference experiment pivoted around a reference trip for a specific working day. Future research could be improved by collecting multi-day information to understand how (and to which extent) day-to-day variation occurs. In particular, understanding how constraints vary (or not) from day-to-day could prove useful to disentangle to what extent the observed behavior is driven by underlying habit and inertia, and external constraints (other than having fixed work hours), such as school start hours, etc. Furthermore, the sample in this study is (as outline above) to a large extent made up of academics, and cannot claim to be representative of the Danish (or even Copenhagen) population. In future work, it would be interesting to explore if our findings holds for a large(r) and more representative population.

\section{Acknowledgement}

The research was conducted during the first author's research exchange at the Institute for Choice, University of South Australia and the first author would like to thank the academic and administrative staff for their hospitality and constructive feedback. The research was partly funded by The Independent Research Fund Denmark, Otto Mønsted Fonden, Cowi Fonden, Reinholdt W. Jorck og hustrus Fond, P. A. Fiskers Fond, Hedorfs Fond, IDAs og Berg-Nielsens Studie- og Støttefond. 


\section{Declaration of Competing Interest}

The authors declare that they have no known competing financial interests or personal relationships that could have appeared to influence the work reported in this paper.

\section{References}

Ajzen, I., 2002. Residual effects of past on later behavior: habituation and reasoned action perspectives. Personal. Soc. Psychol. Rev. 6, 107-122. https://doi.org/10. 1207/S15327957PSPR0602 02.

Ajzen, I., 1991. The theory of planned behavior. Organ. Behav. Hum. Decis. Process. 50, 179-211. https://doi.org/10.1016/0749-5978(91)90020-T.

Arellana, J., Daly, A., Hess, S., Ortúzar, J. de D., Rizzi, L.I., 2012. Development of surveys for study of departure time choice two-stage approach to efficient design. Transp. Res. Rec. 9-18. https://doi.org/10.3141/2303-02.

Arnott, R., Small, K., 1994. The economics of traffic congestion. Am. Sci. 82, 446-455.

Asensio, J., Matas, A., 2008. Commuters valuation of travel time variability. Transp. Res. Part E Logist. Transp. Rev. 44, 1074-1085.

Bamberg, S., Ajzen, I., Schmidt, P., 2003. Choice of travel mode in the theory of planned behavior: the roles of past behavior, habit, and reasoned action. Basic Appl. Soc. Psych. 25, 175-187. https://doi.org/10.1207/S15324834BASP2503_01.

Bauer, G., 2018. The impact of battery electric vehicles on vehicle purchase and driving behavior in Norway. Transp. Res. Part D Transp. Environ. 58, 239-258. https://doi.org/10.1016/j.trd.2017.12.011.

Bhat, C.R., Dubey, S.K., Nagel, K., 2015. Introducing non-normality of latent psychological constructs in choice modeling with an application to bicyclist route choice. Transp. Res. Part B Methodol. 78, 341-363. https://doi.org/10.1016/j.trb.2015.04.005.

Bianchi, R., Jara-Diaz, S.R., Ortúzar, J. de D., 1998. Modelling new pricing strategies for the Santiago Metro. Transp. Policy 5, $223-232$.

Bierlaire, M., 2016. PythonBiogeme : a short introduction, in: Report TRANSP-OR 160706, Series on Biogeme. p. Transport and Mobility Laboratory, School of Archi.

Bogers, E., Viti, F., Hoogendoorn, S., 2005. Joint modeling of advanced travel information service, habit, and learning impacts on route choice by laboratory simulator experiments. Transp. Res. Rec. J. Transp. Res. Board 1926, 189-197. https://doi.org/10.3141/1926-22.

Bowman, J.L., Ben-Akiva, M.E., 2000. Activity-based disaggregate travel demand model system with activity schedules. Transp. Res. Part A Policy Pract. 35, 1-28. https://doi.org/10.1016/S0965-8564(99)00043-9.

Börjesson, M., 2008. Joint RP-SP data in a mixed logit analysis of trip timing decisions. Transp. Res. Part E Logist. Transp. Rev. 44, 1025-1038. https://doi.org/10. 1016/j.tre.2007.11.001.

Cantillo, V., De Dios Ortúzar, J., Williams, H.C.W.L., 2007. Modeling discrete choices in the presence of inertia and serial correlation. Transp. Sci. 41, 195-205. https://doi.org/10.1287/trsc.1060.0178.

Carrus, G., Passafaro, P., Bonnes, M., 2008. Emotions, habits and rational choices in ecological behaviours: The case of recycling and use of public transportation. J. Environ. Psychol. 28, 51-62. https://doi.org/10.1016/j.jenvp.2007.09.003.

Cerrato, J., Cifre, E., 2018. Gender inequality in household chores and work-family conflict. Front. Psychol. 9. https://doi.org/10.3389/fpsyg.2018.01330.

Chatterjee, K., 2011. Modelling the dynamics of bus use in a changing travel environment using panel data. Transportation (Amst) 38, 487-509. https://doi.org/10. 1007/s11116-010-9312-y.

Cherchi, E., Manca, F., 2011. Accounting for inertia in modal choices: some new evidence using a RP/SP dataset. Transportation (Amst) 38, 679-695. https://doi.org/ 10.1007/s11116-011-9338-9.

Cherchi, E., Meloni, I., Ortúzar, J. de D., 2014. The latent effect of inertia in the modal choice. In: Roorda, M.J., Miller, E.J. (Eds.), Travel Behaviour Research: Current Foundations, Future Prospects. Lulu.com Publishers, USA, pp. 517-534.

Christiansen, H., Skovgaard, B.Z., 2015. Documentation of the Danish National Travel Survey. DTU Transport, Data- and Modelcenter.

Conner, M., Sheeran, P., Norman, P., Armitage, C.J., 2000. Temporal stability as a moderator of relationships in the Theory of Planned Behaviour. Br. J. Soc. Psychol. 39, 469-493. https://doi.org/10.1348/014466600164598.

Daly, A., Hess, S., Patruni, B., Potoglou, D., Rohr, C., 2012. Using ordered attitudinal indicators in a latent variable choice model: a study of the impact of security on rail travel behaviour. Transportation (Amst) 39, 267-297. https://doi.org/10.1007/s11116-011-9351-z.

Daziano, R.A., Bolduc, D., 2013. Incorporating pro-environmental preferences towards green automobile technologies through a Bayesian hybrid choice model. Transp. A-Transport Sci. 9, 74-106. https://doi.org/10.1080/18128602.2010.524173.

de Jong, G., Daly, A., Pieters, M., Vellay, C., Bradley, M., Hofman, F., 2003. A model for time of day and mode choice using error components logit. Transp. Res. Part E Logist. Transp. Rev. 39, 245-268.

Fjellinjen, 2015. Oslo bomring: betaling og priser [WWW Document]. URL http://www.fjellinjen.no/Betaling-og-priser/.

Gardner, B., 2009. Modelling motivation and habit in stable travel mode contexts. Transp. Res. Part F Traffic Psychol. Behav. 12, 68-76. https://doi.org/10.1016/j.trf. 2008.08.001.

Golob, T.F., Kitamura, R., Long, L., 1997. Panel for transportation planning. Methods and Applications. Kluwer Academic Publishers, Dordrecht.

Gärling, T., Axhausen, K.W., 2003. Introduction: Habitual travel choice. Transportation (Amst) 30, 1-11. https://doi.org/10.1023/A:1021230223001.

Hansen, M., Huang, Y., 1997. Road supply and traffic in California urban areas. Transp. Res. Part A Policy Pract. 31, 205-218. https://doi.org/10.1016/S09658564(96)00019-5.

He, Z., Yang, L., Guan, W., 2014. A day-to-day route choice model based on travellers' behavioural characteristics. Procedia - Soc. Behav. Sci. 138, 738-747. https:// doi.org/10.1016/j.sbspro.2014.07.251.

Hendrickson, C., Planke, E., 1984. The flexibility of departure times for work trips. Transp. Res. Part A Policy Pract. 18, 25-36.

Hess, S., Polak, J.W., Daly, A., Hyman, G., 2007. Flexible substitution patterns in models of mode and time of day choice: new evidence from the UK and the Netherlands. Transportation (Amst). 34, 213-238.

Jansson, J., Marell, A., Nordlund, A., 2009. Elucidating green consumers: a cluster analytic approach on proenvironmental purchase and curtailment behaviors. J. Euromarketing 18, 245-267. https://doi.org/10.1080/10496480903364242.

Jensen, A.F., Cherchi, E., Mabit, S.L., 2013. On the stability of preferences and attitudes before and after experiencing an electric vehicle. Transp. Res. D Transp. Environ. 25, 24-32. https://doi.org/10.1016/j.trd.2013.07.006.

Kamargianni, M., Ben-Akiva, M., Polydoropoulou, A., 2014. Incorporating social interaction into hybrid choice models. Transportation (Amst) 41, 1263-1285. https:// doi.org/10.1007/s11116-014-9550-5.

Knussen, C., Yule, F., MacKenzie, J., Wells, M., 2004. An analysis of intentions to recycle household waste: The roles of past behaviour, perceived habit, and perceived lack of facilities. J. Environ. Psychol. 24, 237-246. https://doi.org/10.1016/j.jenvp.2003.12.001.

Kroes, E., Daly, A., Gunn, H., Van, D.H., 1996. Opening of the Amsterdam ring road: A case study on short-term effects of removing a bottleneck. Transportation (Amst) $23,71-82$.

Lanzini, P., Khan, S.A., 2017. Shedding light on the psychological and behavioral determinants of travel mode choice: A meta-analysis. Transp. Res. Part F Traffic Psychol. Behav. 48, 13-27. https://doi.org/10.1016/j.trf.2017.04.020.

Lawrence, C., Zhou, J., L., André, L., 1997. User's Guide for CFSQP Version 2.5: A C Code for Solving (Large Scale) Constrained Nonlinear (Minimax) Optimization Problems, Generating Iterates Satisfying All Inequality Constraints.

Likert, R., 1932. A technique for the measurement of attitudes. Arch. Psychol. 22, 5-55.

Lizana, P., Arellana, J.A., Ortúzar, J. de D., Rizzi, L.I., 2013. Modelling mode and time-of-day choice with joint RP And SC data. In: International Choice Modelling Conference. Sydney, Australia, pp. 1-20. 
Louviere, J.J., Hensher, D.A., Swait, J.D., 2000. Stated choice methods: analysis and application. Cambridge University Press, New York.

Noland, R.B., Lem, L.L., 2002. A review of the evidence for induced travel and changes in transportation and environmental policy in the US and the UK. Transp. Res. Part D Transp. Environ. 7, 1-26. https://doi.org/10.1016/S1361-9209(01)00009-8.

Ouellette, J., 1998. Habit and intention in everyday life: The multiple processes by which past behavior predicts future behavior. Psychol. Bull 124.

Paulssen, M., Temme, D., Vij, a., Walker, J., 2014. Values, attitudes and travel behavior: a hierarchical latent variable mixed logit model of travel mode choice. Transportation (Amst) 41, 873-888. https://doi.org/10.1007/s11116-013-9504-3.

Peer, S., Verhoef, E., Knockaert, J., Koster, P., Tseng, Y.Y., 2015. Long-Run versus short-run perspectives on consumer scheduling: Evidence from a revealed-preference experiment among peak-hour road commuters. Int. Econ. Rev. (Philadelphia) 56, 303-323. https://doi.org/10.1111/iere.12103.

Prato, C.G., Bekhor, S., Pronello, C., 2012. Latent variables and route choice behavior. Transportation (Amst) 39, 299-319. https://doi.org/10.1007/s11116-0119344-y.

Ralph, K.M., Brown, A.E., 2017. The role of habit and residential location in travel behavior change programs, a field experiment. Transportation (Amst). https://doi. org/10.1007/s11116-017-9842-7.

Sharmeen, F., Timmermans, H., 2014. Walking down the habitual lane: analyzing path dependence effects of mode choice for social trips. J. Transp. Geogr. 39, 222-227. https://doi.org/10.1016/j.jtrangeo.2014.07.012.

Small, K.A., 1982. The scheduling of consumer activities: work trips. Am. Econ. Rev. 72, 467-479. https://doi.org/10.1126/science.151.3712.867-a.

Spagnola, M., Fiese, B.H., 2007. Family routines and rituals: A context for development in the lives of young children. Infants Young Child. https://doi.org/10.1097/ 01.IYC.0000290352.32170.5a.

Srinivasan, K.K., Bhargavi, P., 2007. Longer-term changes in mode choice decisions in Chennai: a comparison between cross-sectional and dynamic models. Transportation (Amst) 34, 355-374. https://doi.org/10.1007/s11116-007-9116-x.

Starrels, M.E., 1994. Husbands' involvement in female gender-typed household chores. Sex Roles 31, 473-491. https://doi.org/10.1007/BF01544202.

Thorhauge, M., 2015. Departure time choice: Modelling individual preferences, intention and constraints.

Thorhauge, M., Cherchi, E., Rich, J., 2016a. How flexible is flexible? Accounting for the effect of rescheduling possibilities in choice of departure time for work trips. Transp. Res. Part A Policy Pract. 86, 177-193. https://doi.org/10.1016/j.tra.2016.02.006.

Thorhauge, M., Cherchi, E., Rich, J., 2014. Building efficient stated choice design for departure time choices using the scheduling model : Theoretical considerations and practical implementations. In: Presented at Aalborg Trafikdage 2014. Aalborg University, Aalborg, Denmark, pp. 1-15.

Thorhauge, M., Cherchi, E., Walker, J.L., Rich, J., 2017. The role of intention as mediator between latent effects and behavior: application of a hybrid choice model to study departure time choices. Transportation (Amst) 1-25. https://doi.org/10.1007/s11116-017-9839-2.

Thorhauge, M., Haustein, S., Cherchi, E., 2016b. Accounting for the Theory of Planned Behaviour in departure time choice. Transp. Res. Part F Traffic Psychol. Behav. 38, 94-105. https://doi.org/10.1016/j.trf.2016.01.009.

Thøgersen, J., 2006. Understanding repetitive travel mode choices in a stable context: A panel study approach. Transp. Res. Part A Policy Pract. 40, 621-638. https:// doi.org/10.1016/j.tra.2005.11.004.

Transportstyrelsen, 2015a. Trangselskatt i Stockholm: Tider och belopp i Stockholm [WWW Document]. URL https://www.transportstyrelsen.se/sv/vagtrafik/ Trangselskatt/Trangselskatt-i-stockholm/Tider-och-belopp-i-Stockholm/.

Transportstyrelsen, 2015b. Trangselskatt i Göteborg: Tider och belopp i Goteborg [WWW Document]. URL http://www.transportstyrelsen.se/sv/vagtrafik/ Trangselskatt/Trangselskatt-i-goteborg/Tider-och-belopp-i-Goteborg/.

Triandis, H.C., 1977. Interpersonal behavior. Brooks/Cole Pub. Co., Monterey, Calif., USA.

Valeri, E., Cherchi, E., 2016. Does habitual behavior affect the choice of alternative fuel vehicles? Int. J. Sustain. Transp. 10, 825-835. https://doi.org/10.1080/ 15568318.2016.1163445.

van der Waerden, P., Timmermans, H., da Silva, A.N.R., 2015. The influence of personal and trip characteristics on habitual parking behavior. Case Stud. Transp. Policy 3, 33-36. https://doi.org/10.1016/j.cstp.2014.04.001.

Walker, J., Ben-Akiva, M., 2002. Generalized random utility model. Math. Soc. Sci. 43, 303-343. https://doi.org/10.1016/S0165-4896(02)00023-9.

Walker, J.L., Ben-Akiva, M., Bolduc, D., 2007. Identification of parameters in normal error component logit-mixture (NECLM) models. J. Appl. Econom. 22, 1095-1125. https://doi.org/10.1002/jae.971.

Yáñez, M.F., Cherchi, E., Ortúzar, J. de D., Heydecker, B.G., 2009. Inertia and shock effects on mode choice panel data: implications of the Transantiago implementation. In: 12th International Conference on Travel Behaviour Research. Jaipur, India.

Zong, F., Tian, Y., He, Y., Tang, J., Lv, J., 2019. Trip destination prediction based on multi-day GPS data. Phys. A Stat. Mech. its Appl. 515, 258-269. https://doi.org/ 10.1016/j.physa.2018.09.090. 